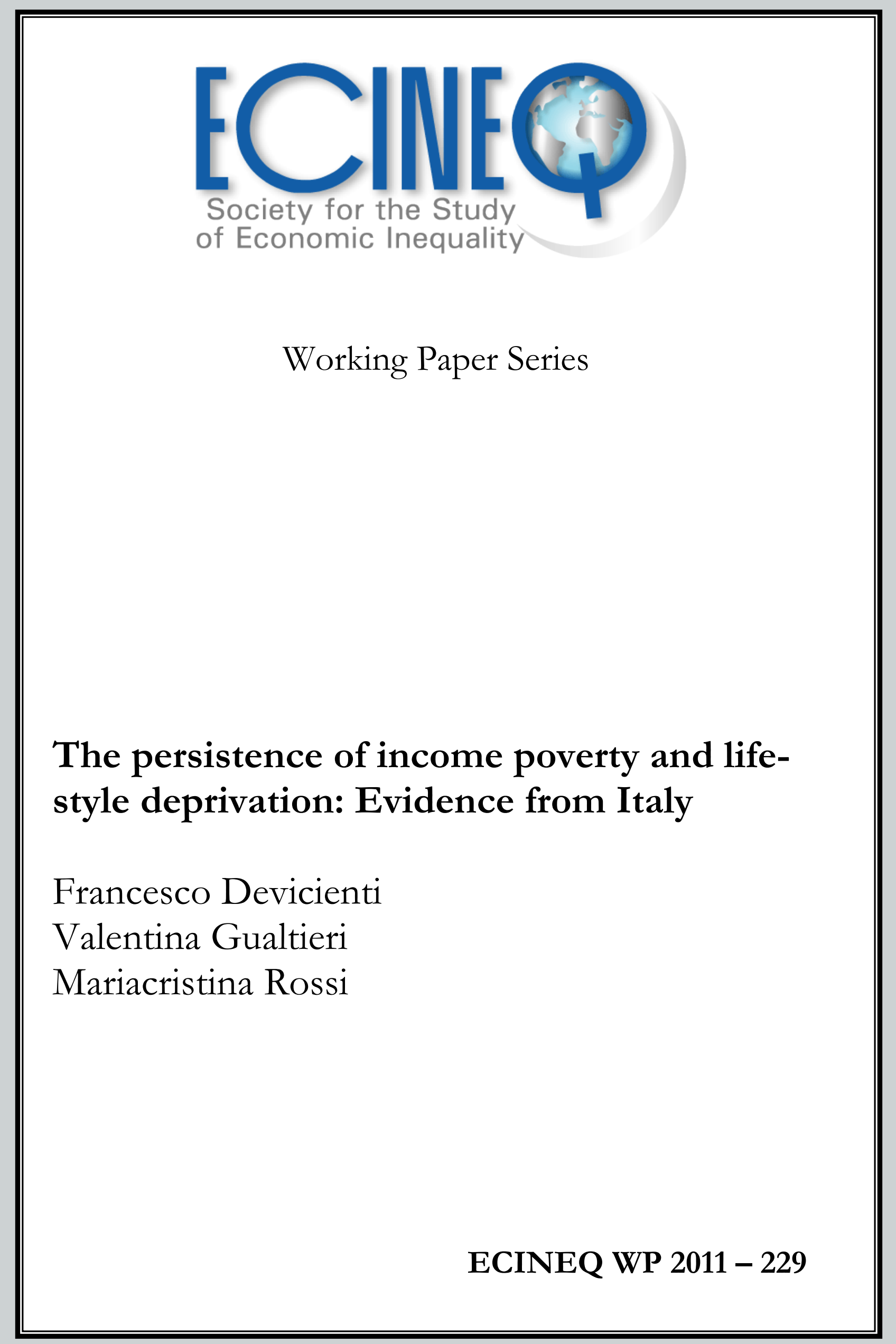




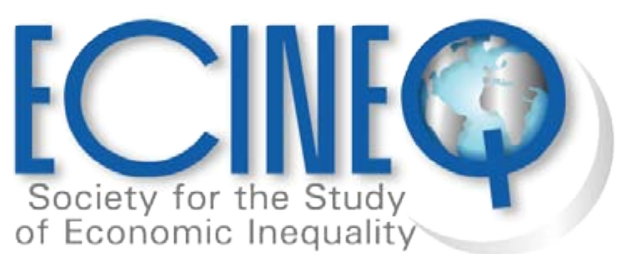

ECINEQ 2011 - 229

November 2011

www.ecineq.org

\title{
The persistence of income poverty and life- style deprivation: Evidence from Italy
}

\author{
Francesco Devicienti ${ }^{*}$ \\ University of Torino and Collegio Carlo Alberto \\ Valentina Gualtieri \\ Institute for the Development of $V$ ocational Training for $W$ orkers \\ Mariacristina Rossi \\ University of Torino and Collegio Carlo Alberto
}

\begin{abstract}
This article estimates poverty persistence over an individual's lifetime, using two definitions: income poverty and a multidimensional index of life-style deprivation. We stressed the ability of the two definitions to provide a generally consistent characterization of poverty persistence risks faced by various population subgroups, but also the additional insights to be gained by analyzing the two definitions in parallel in a longitudinal context. The results of multiple-spell hazard rate models highlight the weaknesses of the Italian labour market, the insufficiencies of the existing social security system and the deep territorial dualism in generating persistent poverty for certain groups of the population.
\end{abstract}

Keywords: Income poverty, multidimensional deprivation, poverty persistence, hazardrate models, multiple spells.

JEL classification: I32, C33.

\footnotetext{
* Contact details: Francesco Devicienti, Dipartimento di Scienze Economiche e Finanziarie "G. Prato", Università di Torino - Facoltà di Economia, Corso Unione Sovietica 218bis, 10134 Torino (Italy), Tel: +39 0116706288, email: fdevicienti@gmail.com
} 


\section{INTRODUCTION}

In recent years, the empirical literature on poverty has made substantial progress in the field's knowledge of the characteristics and determinants of individual longitudinal poverty experiences. Following the contribution of Stevens (1999), the importance of measuring poverty persistence, accounting for the chances of both leaving and re-entering poverty over an individual's lifecycle, is now increasingly appreciated. Despite these developments, some issues remain relatively unexplored. While the vast majority of studies on poverty persistence only focus on the dynamics of low income, many approaches to complement traditional measurement based on income or expenditure have emerged in the last decades (e.g., Deutsch and Silber, 2005), partly reflecting dissatisfaction with traditional monetary approaches, and partly as a genuine reflection of the complexity and multidimensionality of the phenomenon studied.

It is still unclear as to whether this new knowledge of the dynamics and persistence of low income extends to these multidimensional measures of poverty. The multiple-spell approach pioneered by Stevens (1999) has only been applied to a few countries, primarily Englishspeaking countries (e.g., Stevens for the United States; Jenkins, Rigg and Devicienti, 2001, and Devicienti, 2011, for Britain), and it is yet unclear to what extent their results can be extended to countries with different demographics, labor market institutions and social welfare systems.

This article aims to contribute to the empirical literature on poverty persistence on both issues. Our first intent is to study in parallel the dynamics and persistence of two different definitions of poverty-income poverty (IP), and a multidimensional index of life-style deprivation (LSD), obtained by combining the survey's information on the possession of a number of items deemed "essential” in contemporary western life. We analyze the persistence of poverty according to these definitions for both theoretical and empirical reasons. The life cycle theory of consumption, dating back to Modigliani and Brumberg (1954), posits that an individual's welfare depends on attainable consumption, which in turn depends on permanent rather than current income. Hence, in theory, consumption represents a more accurate proxy of a 
household's standard of living than does current income. Yet, longitudinal household surveys do not generally contain consumption expenditure measures, while they increasingly ask families about the possession of a number of durable goods and use of a number of services. Empirical researchers seeking to study the longitudinal aspects of poverty can therefore rely on both the observed individual income sequence and the longitudinal sequence of multidimensional deprivation. While the two sequences have the potential to supply information for the unobserved consumption profile over an individual's lifecycle, both remain only proxies of the underlying phenomenon. Moreover, many researchers may still prefer to look at multidimensional measures of poverty even if longitudinal consumption measures were available (e.g., Sen, 1985; Berthoud et al. 2004). At the very minimum, a parallel analysis of the two poverty definitions can be justified as a robustness check over one’s preferred approach.

The literature analyzing the dynamics of low income finds that, despite frequent re-entry, exits are relatively rapid, making most spells of low income of short duration. It must then be considered how far this result remains valid if poverty is defined in terms of multidimensional deprivation, and whether the groups with high risk of persistent IP are similar in terms of their demographic and labor market characteristics to the groups with high risks of persistent multidimensional deprivation. To the best of our knowledge, our work is the first to apply Stevens (1999)'s multi-spell approach to measuring persistence when poverty is defined without directly referring to income. We will be unable to rank the two approaches according to their ability to reproduce the underlying longitudinal poverty patterns in terms of consumption expenditure, as the latter is unavailable in our panel data. In light of this, our parallel analysis of the two approaches is intended to shed light on their ability to provide a consistent characterization of the dynamics and persistence of poverty.

Our second contribution is to focus on Italy, a country for which the dynamics and persistence of poverty have been little studied before now. One of the largest economies in Europe, Italy is characterized by a longstanding territorial dualism, with a stagnant and 
underdeveloped South, and a poorly-performing labor market. In fact, Italy has earned several negative distinctions, such as the highest rate of long-term unemployment, the highest youth unemployment rate, the lowest participation rate of women and older workers, and the lowest employment rate, which is far from the target of 70 percent set by the European Union for 2010 (European Commission, 2002). Italy also features a poorly-designed social security system (Ferrera, 2005), characterised by a traditional sectorial logic of intervention, one of the lowest shares in Europe of public expenses directed to social assistance and the highest to pensions, and no minimum income guarantee. These circumstances are typically held responsible for the levels of income inequality and the incidence of relative poverty in Italy, both among the highest in Europe. This paper will investigate their potential role in the generation of a deprivation status that persists over time for particular groups of the population.

The availability of 8 waves of the European Community Household Panel (ECHP) enables this study over an extended time period, through the lens of both a low-income and a multidimensional deprivation approach. ${ }^{\mathrm{i}}$ Our empirical analysis is based on multiple-spell models of transitions in and out of poverty, controlling for observed and unobserved individual heterogeneity. The models are estimated separately for both poverty definitions; however, the exit and re-entry rates are estimated jointly to allow for correlated unobserved heterogeneity in the two hazards. The estimates of the models are then used to predict the persistence of poverty among various population groups, noting those that should attract greater policy attention.

Our results provide a picture of high poverty turnover according to both definitions. As discussed in our conceptual framework section, the timing of this turnover is not expected to be completely synchronized across the two definitions, and in fact our empirical results show that, in any given time period, a significant fraction of individuals are poor according to one definition but not the other. We also report that, because of their intrinsic differences, IP and multidimensional deprivation have the ability to complement each other, and therefore to provide 
the analyst with a richer picture of the longitudinal patterns of poverty, in line with the results of Perry (2002), Whelan et al. (2004) and Whelan and Maitre (2006).

However, the empirical analysis also shows that IP and life-style deprivation are sufficiently correlated so that they can both be assumed to provide reasonable, albeit noisy, proxies of the underlying standard of living. Overall, our simulation exercises stress the ability of the two approaches to provide a generally consistent characterization of the risk of poverty persistence faced by various population subgroups, but also the additional insights to be gained from a longitudinal analysis of the two definitions in parallel. The model estimates also highlight the role of demographic characteristics, the insufficiencies of the existing social security system, and, above all, the weaknesses of the Italian labor market and the deep territorial dualism in generating persistent poverty for certain subgroups of the population.

\section{CONCEPTUAL FRAMEWORK}

Before undertaking the empirical analysis it is useful to discuss the theoretical differing implications that the two poverty definitions might have for estimating poverty persistence. Suppose that we could observe both a household's current income and consumption expenditure. The life-cycle theory of consumption would then enable us predict the dynamics of consumption and income: since wealth holdings and borrowing usually make it possible to smooth consumption, the latter tend to be less volatile than income (e.g., Deaton and Muellbauer, 1980 and Deaton, 1992). These theoretical considerations also discredit the use of current income in poverty analysis when high-quality consumption data are available. Consumption, being a choice of which resources to consume today rather than tomorrow, better summarizes the resources available to a family over its lifetime and therefore its standards of living.

Our interest in this paper is not with volatility per se, but rather with the persistence of poverty for those who have just have slipped below the poverty line. ${ }^{\text {ii }}$ Consider an individual with both income and consumption levels above the poverty line who is subsequently hit by a 
negative income shock sufficient to bring income below the poverty line. If the shock was completely anticipated, and therefore already incorporated into the consumer's permanent income, it need not affect consumption, which remains above the line. In this case, the spells of IP observed in the data do not reflect a real situation of deprivation, highlighting an important limitation of the use of current income in longitudinal poverty analyses.

Alternatively, an unanticipated shock implies a downward revision of the consumer's permanent income and, therefore, a drop in current consumption, however smaller than the original shock as the drop in consumption can be spread over many future periods. A sufficiently large shock may make the individual also consumption poor. An immediate implication of this discussion, then, is that, once a common poverty line has been set in monetary terms, consumption poverty spells are less frequent than are IP spells. Further, a drop in consumption smaller than income but large enough to make the individual consumption poor is likely to materialize only some time after the income shock has occurred, because the individual can initially resort to accumulated wealth to sustain consumption. When income does recover from the shock, consumption will in turn increase, but again with a time lag, as the individual's wealth holdings will need to be restored. It is thus likely that, despite the different magnitudes of drops in both consumption and in income, the length of time the individual remains below the poverty line will not differ greatly in the two cases. Further, if financial imperfections are widespread, consumption is bound to follow the dynamics of income more closely, making the expected duration of the two processes even more similar. ${ }^{\text {iii }}$

Yet, several factors are at work that might weaken the link between ex-ante theoretical predictions and the empirical evidence. An important complication derives from the conceptual differences between the theoretical model's variables-income and consumption expendituresand the variables typically used in empirical poverty analyses. In the latter context, household income is generally deflated by an equivalence scale factor. Additionally, in many panel datasets, including our own, the level of consumption expenditure is not observed and the 
researcher can, at best, resort to a summary indicator of lack of “necessary” goods. Consumption expenditure and the indicator of deprivation, which we dub below "life-style deprivation", are correlated, however imperfectly. While a fully-developed theory for the dynamics of equivalent income and LSD is currently missing, the following conceptual framework will guide much of our discussion in the rest of the paper. We consider the LSD score as a comprehensive "outcome variable" reflecting a household's ability to reach a minimum standard of living, as a function $\mathrm{F}(\cdot)$ of its total monetary resources (income and wealth), its level of needs, and a set of "additional constraints" faced by the household, including local prices, availability of infrastructure and public services, and community/family in-kind help:

LSD score $=F($ household income and wealth; household needs; other constraints ...).

Alternatively, the definition of equivalent income implies that this is a function $\mathrm{G}(\cdot)$ of a household's total current income (but not wealth) and some of its needs, specifically only those incorporated in the equivalence scale used. For instance, the needs incorporated by the OECD scales often used in comparative poverty analyses only relate to a household's demographic composition (number of adults and children):

Equivalent income $=G($ household income; demographic needs reflected in the eq. scale).

This conceptual framework helps us predict the differing longitudinal behavior of the two measures. In the case of an exogenous shock, such as the arrival or departure of a child, equivalent income mechanically decreases as the denominator increases in a way dictated by the equivalence scale factor. The welfare implications of this are only valid to the extent that one assumes the normative value judgments built into the particular equivalence scale used. Instead, the LSD score, as a comprehensive outcome variable, decreases if the arrival of the child implies 
a decrease in the household's minimum standard of living, after accounting for the response of the household to the shock. For example, the household may have resorted to various coping strategies to reduce the length of time in deprivation, including dissavings and borrowing.

In another example, a household with total expenditures below the poverty threshold can improve its deprivation index by purchasing less expensive or lower-quality versions of the "necessary" goods and services available to most consumers. A deprived household might also receive in-kind transfers from relatives or their local community, which may improve deprivation scores while leaving unchanged current equivalent income. Thus it can be easier to escape LSD poverty than IP. This conceptual framework suggests entire categories of shocks that are disregarded by the equivalent income definition but that may be captured by the lifestyle deprivation measure. An example is the aggravation of the health status of a non-working elderly member of the household. If this condition does not attract monetary subsidy from the state, the equivalent income will be clearly unaffected. The life-style deprivation measures, however, may increase if the household is forced to spend a significant amount of its monetary resources on the purchase of health or long-term care services.

As the next session will show, many operational choices must be made in order to construct an empirical measure of deprivation from a survey's questions on a household's ability to afford a list of goods and services. The choice of the poverty line to be used for IP and LSD is of particular concern. The empirical guidance offered by the life-cycle consumption theory discussed above is reduced because the non-monetary nature of LSD measures implies that a common monetary poverty line cannot be set. As a practical strategy the dynamic behavior of LSD can be viewed under a number of alternative thresholds, and then compared with that of IP. While this compromise strategy appears justified, it clearly weakens the link between the canonical model's predictions and the dynamic behavior of the empirical measures actually used in poverty analysis. 
Another complication derives from the fact that the canonical model of life-cycle consumption refers to the behavior of a single individual, whereas poverty analyses require that all incomes and consumption expenditures of each household member be simultaneously considered. For example, the canonical model has different implications depending on in which part of the life-cycle the individual is currently living, but households generally consist of members who may be at rather different parts of their life-cycle. While the empirical analysis can try to account for these and other family differences, the theoretical model's predictions of the dynamics of income and consumption are less clear once the entire household is taken into account.

The link between the theoretical predictions and the empirical analysis is further weakened in the presence of measurement error in income, equivalent income, consumption expenditure, or LSD scores. While many studies emphasize that income measurement errors inflate the true extent of mobility across the poverty line (e.g., Lee et al., 2009; Breen and Moisio, 2004), there is little evidence for the relative importance of measurement errors in determining the dynamics of IP and consumption poverty. Although our LSD measures are derived from direct questions on enforced lack of a number of goods and services, measurement error cannot be ruled out entirely.

For these reasons, we argue that the actual longitudinal behavior of IP and LSD is an empirical issue. Furthermore, we stress that when consumption expenditure data are not available, both measures should be considered, as LSD is correlated to consumption in a different way than income. As both measures present limitations, the use of both can only augment the comprehension of the underlying poverty phenomenon over the life cycle.

\section{DATA AND DEFINITIONS}

The data used for our analysis come from the ECHP, which contains detailed income and socio-economic information for a representative sample of national families and their members, 
interviewed first in 1994 and then at successive yearly intervals until 2001. ${ }^{\text {iv }}$ Our first measure identifies poverty in terms of low income, using definitions that have become fairly standard in the international literature (e.g., Jarvis and Jenkins, 1997; Jenkins, 2000; Cappellari and Jenkins, 2004; Biewen, 2006; Cantó Sanchez, 2002 and 2003; Valletta, 2006; Brandolini and Saraceno, 2007). The unit of analysis is the individual, both adults and children. In each survey year, household income refers to the previous year and is computed by summing the incomes of all household members, including income from employment, investment, private property, private transfers, pension income and other social transfers. All monetary values are converted to 2002 prices using the CPI provided by the Italian National Statistical Office. To account for varying household size and composition, household net income is divided by the OECD-modified equivalence scale, and the resulting value is equally attributed to all household members. ${ }^{\mathrm{v}}$ To be considered poor in a given survey year, one's household net equivalent income per person (equivalent income, for short) must be below the poverty line set for the same year. Following EU practice, the poverty line for year $t$ is fixed at 60 percent of the median equivalent income of the same year. An alternative line is obtained by fixing the threshold at 60 percent of the median equivalent income of the first wave (1994) and keeping this same value, in real terms, for successive waves.

The second method used to identify poverty, inspired by Sen’s capability approach (1985), is based on assembling the ECHP information on household deprivation of items for which large diffusion in Italian society makes them tantamount to "essential” durable goods and services (see also Deutsch and Silber, 2005; Muffels and Fourage, 2004). Following Whelan and Maitre (2006), the following 13 items was considered in the analysis, where in each case the item's lack is indicative of a household's inability to afford the item due to its financial situation: (1) colour TV, (2) washing machine, (3) telephone, (4) automobile, (5) video recorder, (6) microwave, (7) adequate heating, (8) 1-week holiday away, (9) replacing any worn-out furniture, (10) new, rather than second-hand, clothes, (11) meat or fish every other day, if desired, (12) hosting 
friends or family for a drink or meal at least once a month, and (13) paying scheduled mortgage payments, utility bills or purchase installments during the past 12 months.

This perspective is in essence multidimensional, even though the constituent indicators are then summarized in a scalar dichotomous indicator of poverty. While this procedure reduces much of the attractiveness of a multidimensional approach, the choice is made for convenience, as longitudinal analyses of individual multidimensional poverty indicators are otherwise intractable. Moreover, it allows us to use the same methodology employed with the (dichotomous) measure of low income. A similar choice is made by Whelan et al. (2004) and Whelan and Maitre (2006), who summarize the set of items in a scalar measure, which they call the index of "life-style deprivation". While our index differs slightly from theirs, we keep the same name for simplicity.

The indicator is constructed as follows. First, for each of the 13 indicators, we construct corresponding dummy indicators equal to 1 when the household is deprived of the item, 0 if not deprived, and missing when the household does not answer the question. Second, the dummy indicators are aggregated on the basis of a set of weights that reflect the item's importance in the summary indicator of life-style deprivation. As in Whelan and Maitre (2006), we weigh each item for the proportion of households not suffering its enforced lack (see Table A1). ${ }^{\text {vi }}$ Finally, the deprivation score for each individual $i$, called $S_{i}$, is made dichotomous by setting a threshold that identifies which households suffer from LSD and which do not in any given year. The choice of threshold is arbitrary and can be assigned on the basis of the existing literature, as we do with IP, or can be chosen in a way that reflects a particular focus. For example, the threshold can be "generous", thereby capturing the type of deprivation suffered by middle-class households, or can be set at a fairly low level, which should instead identify situations of more extreme hardship. We experiment with a range of values for the threshold, from a relatively low value of 70 percent of the median $S_{i}$ as in D'Ambrosio at al. (2008) and Deutch and Silber (2005), to a more generous 85 percent of the median $S_{i}$. In each case the threshold is fixed at a 
fraction of the median $S_{i}$ in wave 1 , in line with our fixed-in-real-terms IP. ${ }^{\text {vii }}$ Note that our thresholds differ from those used by Whelan and Maitre (2006), who set the income threshold first and only then choose the deprivation threshold that guarantees that the incidence of deprivation and low income is the same in each wave. We do not follow this approach because we want to avoid a scenario in which the two poverty definitions are mechanically related by construction, which explains also why an income component is not directly included in the LSD index. As one of our aims is to study two distinct poverty definitions in parallel, without giving priority status to either, we set our deprivation threshold independently from the low-income threshold.

\section{INCOME POVERTY AND LIFE-STYLE DEPRIVATION: PRELIMINARY}

\section{EVIDENCE}

Table 1 adopts a cross-sectional perspective and describes the percentage of individuals considered poor or deprived during the sample period. On average, IP affects 16 percent of the population if the fixed-in-real-terms threshold is used, and 19 percent if the poverty line is allowed to be time-varying. The incidence of LSD is, on average, 9 percent if the 70 percent threshold is used, 15 percent with the 80 percent threshold and 22 percent with the 85 percent threshold (not shown). A direct comparison of the levels of poverty is not particularly informative in any given year, as these levels reflect the (arbitrary) poverty lines chosen. It is therefore more informative to document the aggregate changes in the indicators over time. Between 1994 and 2001, mean household equivalent income increased by 1.7 percent annually in real terms. If IP is measured with a fixed threshold, the growth in income translates to a reduction in the incidence of poverty of about 7 percentage points. If the line is allowed to vary annually, the fall in the incidence of IP is more modest, somewhat reflecting a decline in equivalent income inequality. ${ }^{\text {viii }}$ LSD also has a declining trend over time-the reduction in its incidence over the period is 8 percentage points if using the 80 percent threshold, not very 
different from that of IP measured with the fixed threshold. This parallel trend may be taken as an indication that both measures capture an "absolute” view of poverty, while IP measured with the time-varying threshold is more likely to capture a "relative" concept. The median of $\mathrm{S}_{\mathrm{i}}$ is virtually unchanged during the sample period, implying that the deprivation thresholds are de facto also time-invariant; the decline in the deprivation incidence then reflects growth in the lower percentiles of $\mathrm{S}_{\mathrm{i}}$. ${ }^{\mathrm{ix}}$

To analyze the longitudinal patterns of poverty, and in particular the transitions that individuals make below and above each of the respective poverty thresholds, we now turn to the panel component of the data. Table 2 shows the fraction of the population who experience any number of years in poverty within an 8-year period. A number of findings are worth noting; first, the majority of the population is never hit by poverty. Second, the fraction of the population that is below the poverty threshold in at least one year during the 8-year period is much higher than the cross-sectional poverty rates shown in Table 1 . In fact, 44 percent of the population are affected by IP at least once within the 8-year period-48 percent with a time-varying threshold. In the case of LSD, this same fraction is between 29 percent and 42 percent, depending on the threshold used. Third, among those who experience poverty at least once, poverty is often shown to be temporary. For example, the table demonstrates that 33 percent remain below the (fixed) IP line for only one year in eight; the corresponding figure for LSD at the 80 percent threshold is 35 percent. Forth, the number of people affected by persistent poverty is also fairly high. Among those who fall below the (fixed) low-income threshold, about 40 percent remain poor for at least four years during the sample period; the corresponding figure for LSD is between 26 percent with the 70 percent threshold and 33 percent with the 80 percent threshold. A non-negligible minority of individuals are always in poverty within the 8-year period, which varies between 1 and 3 percent, depending on the definition of poverty used.

Note that the longitudinal calculations discussed above-based on the number of years in poverty and a balanced longitudinal sample—are subject to potentially important limitations that 
we discuss below and seek to overcome with a hazard rate approach beginning in Section 6 . Despite these limitations, we are inclined to derive two broad messages from this preliminary longitudinal analysis. First, these results are consistent with the view that poverty, however defined, is a condition "in movement”, which can hit in transitory, occasional, repeated and persistent ways. The other message is that longitudinal movements in LSD are not necessarily less pronounced than in IP. In general, for any poverty definition, a higher threshold is related to a longer persistence of poverty for those who fall below it. The figures obtained in the case of IP can thus be made lower or higher than the values for LSD by varying the generosity of the thresholds. When the thresholds for IP and LSD are designed to deliver a similar cross-sectional incidence-most notably for the fixed IP and for the 80 percent deprivation threshold - the longitudinal behavior of the two poverty definitions are also similar.

In the following sections these suggestive results will be subject to deeper scrutiny using a multiple-spell hazard rate approach. The persistence of IP and LSD will be analyzed in parallel, applying this approach separately for each definition. This assumes that the two poverty definitions can complement each other, and will thus enrich our understanding of the longitudinal behavior of an underlying material deprivation measure. The next session investigates the extent to which this assumption is tenable.

\section{THE “OVERLAP” BETWEEN INCOME POVERTY AND LIFE-STYLE DEPRIVATION}

IP and LSD are constructed independently, assembling different pieces of survey information; they may capture rather different aspects of a complex and multidimensional phenomenon. Alternatively, they might both measure, with different degrees of accuracy, the same underlying (unobserved) notions of poverty. In this case it is also possible that they overlap substantially, making one of the two measures redundant from an empirical point of view. 
One way to shed some light on this issue is to investigate whether the two types of deprivation are shaped by the same or different sets of demographic and economic factors. Table 3 presents a number of multivariate regressions in which the dependent variable is either IP or LSD. An extensive set of demographic and socio-economic characteristics, at both the household and individual levels, are used as covariates. They are meant to capture the most important determinants of a household's financial situation (e.g., number of members in work, labor market status and education of household head, regional labor market conditions and prices) while reflecting a household's needs, for instance those related to its demographic structure (e.g., number of children or elderly individuals) or the presence of members with serious health problems.

Model (1) presents the marginal effects from a simple probit model for the probability of being income poor in the current year, pooling all 1994-2001 observations and using contemporaneous covariates. Given the significant overlap at the individual level between IP fixed and time-varying thresholds (correlation equal to 0.93), we focus only on the former in the rest of the paper. ${ }^{\mathrm{x}}$ Model (2) is similar, with a dependent variable now a dummy variable that indicates LSD in the current year. Unless otherwise stated, we will focus on the 80 percent threshold for LSD; as the preliminary static and longitudinal patterns are, with this threshold, very similar to the income definition, any differences in their determinants will strengthen our case for the non-redundancy of the two measures. In this section we will only briefly discuss and compare the impact of the covariates across the two types of deprivation. The aim is to provide an assessment of the overlap or mismatch in the determinants of the two poverty definitions; in later sections we will analyze more systematically the impact of the various covariates on poverty persistence through simulation exercises.

Most of the covariates impact the probability of both types of deprivation in the same predictable direction. More children increase the probability of IP in the current year, as well as that of LSD, although the effect is smaller in the latter case. This confirms our ex-ante prediction 
that consumption poverty reflects the additional coping strategies that the household might put into practice; therefore any "shock" to the household, such as additional children, should have a lower impact on consumption level, and therefore, a lower impact on LSD than on IP. A larger number of adult members aged 18 to 64 raises both probabilities. Note that the models already control for the number of working adults in the household; therefore, the variable "number of adults” captures the negative contribution to a household's budget from non-working adults. The effect is stronger (in absolute value) for IP than for LSD, again confirming the above predictions of the conceptual framework. The effect of the number of elderly people in the household (aged 65 or more) is imprecisely measured, and its sign is uncertain.

The incidence of either type of deprivation is lower when a larger number of household members are in paid work ${ }^{\mathrm{xi}}$. The estimated impact is three times larger in the case of IP than in LSD, the former being more directly linked to household monetary resources. Reflecting upward mobility in one's career over the life-cycle, the risks of poverty reduce as the head of household ages, but begins to rise again around age 50 for both IP and LSD, mirroring the decline in the earnings profile in the final stage of a career. Female headship increases the chances of being in poverty, as does lower education of household head (less than secondary education, the reference category), with broadly similar effects across both types of deprivation. A household head that works less than 15 hours a week, or is unemployed, discouraged or inactive (base category: head works normally) significantly increases the chances of being in income deprivation. These effects are higher for IP than for LSD, supporting once more the view that coping strategies to fight poverty other than income-related strategies (e.g., borrowing, access to household wealth and non-market coping strategies) may weaken the relationship between poverty and current income earned by the household head in the labor market.

Those living in the underdeveloped south of Italy as opposed to the centre (the base category) face higher risks of poverty, and the risks are even lower for those living in the prosperous north. These effects are very similar across the two poverty definitions. This result 
may appear somewhat surprising as one might expect that the large, and persistent, income differences between the two areas of the country should translate into higher area differences measured by LSD than by IP. The fact that this does not occur may be explained by the (documented) lower prices of many goods and services faced by southern residents. Differences in the average quality of the goods and services, and the differential recourse to community or family-help or other coping strategies between the two areas is another possibility. LSD can in principle capture these additional circumstances, which may contribute to alleviating the territorial differences in the standards of living arising from large disparities in income.

Other factors that increase the risks of poverty are whether the household head is separated, divorced or single, once again with very similar effects for both IP and LSD. The effect of being a single parent head is also positive. However, in general these variables are not found to be statistically significant in later models looking at poverty persistence. The models also include individual level covariates - the gender of the person and two dummies indicating whether he or she is young (aged 18 or less) or old (aged 64 or more). These variables are often imprecisely estimated, particularly in later models, suggesting that it may be difficult to identify individual-level covariates once a rich set of household-level covariates is already included in the models.

While most factors seem to influence both types of deprivation in the same direction, and often with a similar magnitude, two variables stand out for their opposite effects. Having a selfemployed head increases the chances of IP but reduces the risks of LSD. ${ }^{\text {xii }}$ The most plausible explanation for this finding is the under-reporting of self-employment income. Conversely, the number of adults or elderly individuals in the household who report any chronic physical or mental health problem, illness or disability in the current year has a positive impact on LSD, whereas the effect is negative and statistically insignificant for IP. Given that we already control for a household's needs related to its demographic structure, one possible interpretation of this finding is that LSD is potentially able to reflect additional health-related needs (e.g. health 
expenses), whereas the definition based on equivalent income is not. As remarked in section 2, one should note, in fact, that the OECD equivalence scale, and other scales more generally, make no allowance for these special needs in adjusting household income.

Models (3) and (4) in Table 3 take a longitudinal perspective. They compare the determinants of persistence in LSD and IP. The models are estimated on the sample of all individuals present in survey years $t, t+1, t+2$ and $t+3$, where $t$ is wave 5 , wave 4 or wave 3 . The dependent variable is alternatively a dummy indicating IP in all four years $(t-t+3)$ or a dummy indicating LSD in all four years. Covariates refer to year t. ${ }^{\text {xii }}$ The results of these longitudinal models seem to confirm many of the previous lessons. First, the factors that affect persistent poverty are very much the same factors that affect contemporaneous poverty. Second, these factors impact persistent IP and LSD in the same direction, and in many cases the magnitude of the effect is also similar.

As noted above, however, there are also a few significant exceptions. Having a selfemployed head of household increases the risks of persistent IP but decreases the risks of persistent LSD. The number of health problems in the household also seem to affect the two definitions differently, positively impacting LSD while negatively or insignificantly affecting IP. Third, those factors (number of adults and children in the household) that enter in the definition of the equivalence scale have a stronger effect on IP than on LSD. Those factors related to the labor market (number of members in paid work, the labor market status and education level of the head) also exert a stronger effect on IP.

To further investigate the extent of the "overlap" between the two measures, we now look at the correlation between the two definitions at the individual level. The tetrachoric correlation coefficient between current IP and current LSD is about 0.60. Table 4 explores this association within a multivariate framework, using the same covariates and samples as before. Suppose that the two poverty definitions were measuring essentially the same thing, so that knowledge that a person is, say, in LSD renders superfluous the additional knowledge of his or her IP status. In 
this case a multivariate regression of LSD in which IP is included in the list of covariates should produce a statistically insignificant coefficient for the additional covariate.

This is not what is found in Table 4, however. Model 1 clearly shows that, after controlling for the full set of covariates, knowledge that a person is below the IP threshold in a given year helps predict the probability of being in LSD; in fact, this probability is increased by about 10 percentage points when the person is in IP. Models 2 and 3 include indicators for IP in the current year and in the previous three to five years. The results show that each additional year of poverty has an independent effect on LSD in the current year: those households with low income in the current year have a 3 percentage point (p.p.) higher probability of being in LSD in the same year. Those who have also been in low income for the previous three years have about a 12 p.p. higher risk of LSD. Model 4 shows the effect of persistent IP on the probability of being in persistent LSD, using the same definitions as in Table 3. Having spent the previous four years in IP increases by about 9 p.p. the probability of persistent LSD in the following four years. Model 5 provides an alternative estimate based on simple OLS estimates of the number of years in IP and in LSD, for all individuals observed in each of the 8 waves (balanced panel). Covariates refer to wave 1 in this case. According to column (5) of table 4, each additional year of IP during the 1994-2001 period increases the number of years in life style deprivation by 0.28 .

The existence of this positive correlation should, however, not lead us to expect more than an imperfect overlap between the two measures at the individual level. The raw probability of being LSD, conditional on being income poor in the same year, is approximately 38 percent. $^{\text {xiv }}$ These findings are not new and have led Perry (2002) and Whelan et al. (2004) to conclude that IP and LSD, albeit correlated, are "tapping different phenomena”. This may be due to a number of reasons. First, the "timing" in the evolution of income, with its short-tem fluctuation, does not always translate into changes in a person's well-being, as discussed in Section 2. Second, the presence of household needs (e.g., disabled or unhealthy persons in the household) and circumstances (e.g., differences in local prices) may not be adequately captured 
by the "equivalence scale" factors underlying the IP definitions, whereas it should be more directly related to LSD. Third, individuals long in situations of financial restraint tend to develop coping strategies and forms of adaptability enabling them to reach an acceptable standard of living, or at least one that our life-style indicator measures as such. Finally, income underreporting, measurement errors in both income and the deprivation score, and the incompleteness of the list of deprivation items (which results in a "truncated" distribution of the deprivation score) are also potentially responsible for part of the observed mismatch. While further investigating the reasons for the moderate overlap between the two definitions of poverty is not the aim of this paper, we see these results as a confirmation of the importance of studying the dynamics of poverty from different perspectives.

It is however interesting to provide some elements with which to evaluate the relative ability of the two definitions to represent an underlying notion of low standard of living. If it were possible to observe a person's consumption expenditure, it would be natural to ask which of the two poverty measures better correlates to it. We do not have this information in our data; however, it is possible to assess the correlation of our two poverty measures with indicators of financial satisfaction and of the ability to make ends meet. This is done in Table 5. Financial satisfaction is asked to all adult respondents on a 6 grade scale from not satisfied to fully satisfied. As for the ability to make ends meet, the following question is asked in the ECHP: "A household may have different sources of income and more than one household member may contribute to it. Thinking of your household's total monthly income, is your household able to make ends meet?". Answers are elicited on a 6-grade scale from "with great difficulty" to "very easily". To investigate the correlation of these variables and our measures of poverty, we run ordered logit models using the same sample and list of covariates as before. The results of Table 5 show that both poverty measures are negatively correlated with indicators of financial satisfaction and a household's ability to make ends meet. Interestingly, in all cases the effect is 
higher in the case of LSD than for IP, suggesting that this variable might come somewhat closer than IP to representing an underlying notion of low standard of living.

Overall, we determine from the results of this section that IP and LSD clearly capture very much the same underlying concept of "exclusion from acceptable standard of living through a lack of resources”, and thus are likely to offer two valid proxies for it. At the same time, the existing differences between the factors correlated with both definitions suggest that they have the potential to complement each other by capturing different facets of need and deprivation.

\section{MEASURING POVERTY PERSISTENCE: A HAZARD RATE APPROACH}

The results of the previous sections provide a first attempt at characterizing the longitudinal behavior of IP and LSD, but are subject to potentially important limitations. ${ }^{\mathrm{xv}}$ First, they do not provide an estimate of the total time spent in poverty. The OLS models for the number of years in poverty can do this, in principle, but are subject to censoring biases. Like the statistics in Table 2, they are based on the simple count of the number of years in which individuals are observed to be in poverty. However, those who, at the end of the survey period (2001 in our case), are still in poverty can find themselves in the midst of fairly long spells, although the researcher can only observe them in poverty for a few years. Similarly, those who are already poor when they first enter in the panel (in 1994) may have already been so for many years, although to the observer the individual appears poor only from 1994 onwards. Note that the persistence in poverty computed by OECD (2001), Whelan et al. (2004) and Whelan and Maitre (2006) are all subject to these limitations. A second limitation is that much panel information is thrown out when computing the persistent measures employed in Tables 3 and 4. A related problem is that controlling for time-invariant unobserved heterogeneity is not viable once the longitudinal variability is so collapsed. As discussed by Bane and Ellwood (1986) and Jenkins (2000), the hazard rate approach is particularly well-suited for the study of the dynamics of poverty at the individual level: it is potentially immune to the censoring problem, while 
lending itself to multivariate analyses of the factors associated with transitions in and out of poverty, and hence to estimating poverty persistence over an individual's life-time. Importantly, the approach allows the researcher to assess the effect that time spent in poverty or non-poverty states has on the probability of ending the state. The issue that interests researchers is whether the length of the current spell (duration dependence), as well as past spells of poverty and nonpoverty (occurrence dependence), affects poverty persistence in a "true" sense or is simply the (spurious) effect of uncontrolled individual heterogeneity. In other words, we investigate whether a "scarring effect" of the time already spent in the current spell, or deriving from the time spent in past poverty spells, exists making poverty particularly persistent, other factors assumed equal. The issue has policy relevance, for if true state (duration or occurrence) dependence exists, then short-lived shocks can persist over long periods and policy interventions designed to reduce such shocks could have long-term consequences. Because of its ability to confront these issues while avoiding the limitations of the previous models, we next apply the hazard rate approach in the following sections.

We begin by analyzing the broad patterns of transitions in and out of poverty using simple non-parametric estimates of the hazard rates in and out of poverty (Kaplan-Meier estimates). The sample comprises all spells experienced by individuals with non-missing poverty indicators in two or more consecutive years, having one or more spells of poverty and/or non-poverty. This "unbalanced sample” design should reduce biases deriving from non-random attrition. Note that the present approach accommodates right-censored spells - those that are still in progress at the end of the survey year contribute every year to the estimation of the hazard rate (through its denominator) until the truncation year. On the contrary, as in most of the literature, left-censored spells are not easily accommodated within the framework and are discarded, implying that only spells that begin in wave 2 or successive waves can be considered. ${ }^{\text {xvi }}$ Note that individuals who have always been above the poverty line (more than half of the sample) do not contribute to the spell sample. As these right- and left-censored spells refer to individuals who will hardly 
experience poverty in their lifetime, they do not provide much information on the dynamics of poverty for those who happen to fall below the line. On the contrary, the exclusion of individuals who have always been below the line in each year is more problematic, as they refer to individuals with longer-than-average spells of poverty. While there are methods that allow the researcher to control for the biases that such an exclusion may imply, they are rather demanding from a technical and empirical point of view, which may explain why most of the literature has ignored the issue. Additionally, the few studies that have attempted to include left-censored spells in the analysis (Stevens 1999; Devicienti, 2011) have concluded that the left-censored biases are likely to be of second order in relatively long panels ${ }^{\text {xvii; }}$, note also that, in practice, only a minority (between 1 and 3 percent) of the sample is always below the line in each year of the sample period (Table 2).

Our estimates of hazard and survival functions are displayed in Table 6, separately for each poverty definition. The estimated exit rates in IP hint at the existence of negative duration dependence: the longer an individual stays in poverty the less likely it is that he or she will leave that state in the next period. For the group of individuals that have just begun a spell of poverty, approximately 58 percent succeed in exiting after the first year; after five years the chances of exiting drop to 20 percent. Consequently, 9 percent of those who had been observed to be poor are still so after 6 years. Exit rates follow a similar pattern in the case of LSD, with estimated hazards declining with duration. Of all those who have just started a spell according to this definition of poverty, about 60 percent manage to leave the state after one year. After five years, the hazard is at 25 percent; 19 percent with the 70 percent threshold. Survival in LSD is slightly less likely than in IP: after 7 years, about 6 percent are still in LSD, compared with about 7 percent in IP.

Table 6 also displays the re-entry rates and the survival functions for those who have just terminated a poverty spell. In this case the results also hint at the existence of negative duration dependence: the more an individual remains out of poverty, the less likely it is that he or she will 
fall below the line in the successive periods. Once again, this is true for both IP and LSD. In general, re-entry rates are smaller than exit rates but still point to a significant risk that the individuals fall back below the threshold, particularly in the years just after an exit from poverty has occurred. Approximately 25 percent of the individuals that conclude a spell of IP will be poor again after the first year; after four years, approximately 46 percent of the poverty escapers will have become poor again. Re-entry rates in LSD are very similar to those of IP; after one year out of LSD the probability of re-entry is 25 percent (22 percent with the 70 percent threshold) and, after four years it is 8 percent (10 percent). Not surprisingly, also the survival functions in LSD and in IP are fairly similar.

To summarize, the results of Table 6 confirm that in Italy, contrary to a static view of poverty, there is a fairly significant amount of movement in poverty condition. Although there is a small group of people who are poor in each of the survey years, there is a relatively large number of persons who enter and exit poverty from one year to the next. These dynamic characteristics of poverty have been established empirically for a number of countries in the case of IP. For example, Devicienti (2002) estimates that in Britain approximately one person out of two escapes poverty after one year; after four years the exit rate is at around 20 percent. For the United States, Stevens (1999) reports similar figures: 54 percent for the exit rate after one year, and 23 percent after four years. The re-entry rates after one year is equal to 29 percent in Britain and 27 percent in the United States. While it should be stressed that cross-country comparisons should always be interpreted with caution, it is interesting to note here that these estimates do not differ much from those reported for Italy in Table 6. In addition, here we also show that an equally large amount of turnover emerges when poverty is defined in terms of LSD. ${ }^{\text {xvii }}$

The estimates of the exit and re-entry rates are now combined in order to derive the distribution of the "number of years spent in poverty", which is at the base of the measures of poverty persistence adopted in this paper. The importance of multiple spells in poverty for the same person over a relatively long time period is emphasized by a number of papers (e.g., 
Stevens, 1999; Devicienti, 2011; Jenkins and Rigg, 2001). In fact, in our data about 32 percent of those who end an IP spell will have a second or a third spell during the next seven years, and the percentage is similar for LSD. It seems therefore appropriate to consider poverty persistence measures that can take into account the total number of years that an individual spends in poverty within our 7-year temporal horizon, where it is not required-as it would be in a singlespell framework - that the years in poverty be consecutive. In other words, the measures account for both the chances of exiting and for the risk of successive re-entry to which an individual is subjected. Moreover, computing the "distribution of the number of years in poverty" over multiple spells offers a convenient method with which to summarize the information on the exit and re-entry rates estimated in the previous section. It is then easier to compute and compare measures of poverty persistence for the two definitions of poverty. Two such measures are displayed at the bottom of Table 7, namely the expected number of years in poverty and the percentage of individuals who spend at least four years out of seven in poverty.

We look at IP first. As Table 7 shows, 29 percent of the population will have only one year in poverty of the next seven years, while about 33 percent of those starting an IP spell will spend at least 4 years below the poverty line. It is instructive to compare the poverty persistence over multiple spells obtained for Italy with the results available for Britain, as the same methodology and roughly the same time period was used for both countries-the comparison with the USA would be more problematic as the period analyzed by Stevens (1999) refers to the 1980s, rather than the 1990s. Devicienti (2011) finds that in Britain approximately 41 percent of those who begin a poverty spell will remain poor for at least 4 years once the multiple spells are taken into account. The estimates of the distribution of the number of years in LSD are also shown in the table. When the 80 percent threshold is used, the poverty persistence measures obtained for LSD and IP are almost indistinguishable. Approximately 29 percent of the individuals spend one year out of seven in poverty, and about 33 percent will spend 4 years, according to both poverty definitions. The expected number of years in poverty is 2.9. Poverty persistence in IP is and in 
LSD are similar even if one refers to the percentage of individuals who spend seven years out of seven in poverty, between 6 and 7 percent. The figures for LSD differ slightly when referring to the 70 percent threshold, which implies lower persistence. However, they would be rather similar to the ones obtained when setting IP at a lower threshold, e.g. another commonly used cut-off$50 \%$ of median equivalent income-as shown in the second column.

The results of Table 7 show a somewhat surprising similarity between the persistence in poverty according to the two definitions. The conceptual framework of Section 2 discussed potential reasons for this similarity, but also pointed out in what respect the dynamic behavior of IP and LSD is expected to differ. In fact, the results of Table 7 only suggest that the aspects of similarity seem to prevail at an aggregate level, for the population as a whole. In the next section multivariate hazard rate models will be estimated to further explore how IP and LSD behave longitudinally for various groups of the population. It will emerge that the results of Table 7 hide much population heterogeneity, and in some cases also hide interesting differences between the two definitions of poverty.

\section{MULTIVARIATE ANALYSIS OF POVERTY EXIT AND RE-ENTRY}

\section{Observed household and individual heterogeneity}

The previous analysis assumed that all the observed spells refer to a completely homogeneous population. It is instead more likely that groups of the population with particular observable and unobservable characteristics face different risks of exiting from and re-entering into poverty, and therefore of being persistently poor. To shed light on the identity of these groups we now move to multivariate techniques that allow exit and re-entry rates to depend on important socio-economic correlates of poverty transitions. We use discrete-time multivariate hazard rate models, cloglog formulation (see Prentice and Gloecker, 1978). Our estimation strategy also accounts for spell correlation in the presence of unobserved heterogeneity, as in Stevens (1999); the model's specification and estimation are detailed in our online 
Supplementary Material. For transitions occurring between years $t$ and $t+1$, the covariates refer to the value that the characteristic assumes in year $t$, so as to reduce endogeneity/simultaneity problems with the transitions in and out of poverty, and are allowed to be time varying. The set of covariates included in the hazard rate models is the same as before, and in most cases the impact of covariates upon poverty exit and re-entry rates is consistent with the static and dynamic model results of the previous sections. However, as noted before, the multivariate modeling of poverty hazard rates allows for a much richer characterization of the dynamic experience of poverty for various groups of the population. The results of our hazard rate models are shown in Table 8 for both exit and the re-entry rates. In the interest of brevity we will only report and comment on the results obtained with the joint estimation of the exit and re-entry rates, which control for unobserved heterogeneity. ${ }^{\text {xix }}$

In general, household and individual characteristics impact the probabilities of escaping poverty in predictable ways. Moreover, the variables that make a poverty escape more difficult are also those that make it more likely to fall back into poverty. For example, the number of children in the household has a negative impact on the probability of leaving IP and LSD. The size of the coefficient is larger (in absolute value) for IP than for life style deprivation; however, the effect of the same variable on the re-entry rate is also higher for the first definition of poverty. Therefore, to fully characterize the persistence in IP and LSD of various groups of the population one should resort to simulation methods and to a multiple spell methodology that simultaneously accounts for the chances of exit from and re-entry into poverty. This is aim of the next section; accordingly, in the rest of this section we will limit ourselves to a qualitative overview of the estimated impact of the various covariates.

We first start with the exit rates. As Table 8 shows, exit rates from poverty are lower when there are a large number of children and adults, with a larger effect in the case of IP. Exit rates are instead higher as the number of elderly individuals increases. This latter effect is significant for IP, perhaps reflecting the social security anomalies of the Italian case, in which fairly 
generous pensions imply that, other conditions being equal, the presence of an elderly person increases a family's welfare, at least when the latter is measured in terms of equivalent income. ${ }^{\mathrm{xx}}$ The same variable has a non-significant negative coefficient for LSD, which may suggest that the personal income received by elderly individuals is compensated within the household by their greater needs. The exit rate also increases with the number of household members who work, and the estimated impact is economically larger for IP than for LSD. The literature on poverty dynamics discusses the role of secondary earners (partners, grandparents, etc.) in lifting poor households above the low-income cut-off (OECD, 1998; Jenkins, 2000). We thus provide further empirical support for this argument, by showing its relevance beyond the low-income context.

Reflecting upward mobility in the head of household's career, exit rates increase before dropping at age 46 for IP and age 52 for life style-deprivation. This likely reflects the typical inverse U-shaped earnings profile; for LSD it might indicate the peak of accumulated assets, and thus the buffer stock to use for emergencies. Exit rates are also lower when the household head has less than secondary education; having a university degree, conversely, increases exit rates, but the effect is imprecisely measured. The labor market status of the head also exerts a large impact on exit rate, decreasing it when the head works less than 15 hours a week, or is unemployed, discouraged or inactive (base category: head works normally). These effects are generally higher for IP than for LSD. Nonetheless, the results display the well-known inadequacies of the Italian social security system towards the categories that stay out of the labor market for extended periods of time (e.g., Ferrera, 2005; Baldini et al., 2002; Utili and Rostagno, 1998), as we further elaborate below.

When the household head is self-employed, the hazard of leaving LSD increases, whereas the hazard of leaving IP decreases. This opposite pattern has been noted before and provides further evidence in support of our conjecture that self-employment income might be underreported, and that reference to alternative poverty indicators should be made in order to 
accurately evaluate the longitudinal well-being of this type of household. Living in the underdeveloped and economically depressed South of Italy, as opposed to the centre (the base category) or the prosperous North, further reduces exit rates, according to both definitions and with similar magnitudes. ${ }^{x x i}$ Interestingly, the number of health problems in the household increases the exit rates from IP but has a negative effect for LSD. As noted above, this is consistent with the prediction that health-related needs should be captured by our deprivation measure but are totally ignored by an equivalent income-based measure. However, the estimates in this case are not statistically significant, with the exception of the re-entry rate in LSD, for which the coefficient is positive, as expected.

The other controls considered in the models_dummies for being a child or an elderly member of the household, for the person's gender, and for whether the household head is single, separated or a single parent—do not generally provide clear results, as the coefficients are often statistically insignificant. The effect of the gender of the household head on exit rate is also statistically insignificant for both poverty definitions. The poverty persistence implication of these variables will therefore not be systematically assessed in the simulation exercises of the next session.

In the interest of brevity we will kept our comments of the estimated coefficients for the reentry rates at a minimum ${ }^{\text {xxii }}$, leaving the overall effect of covariates on poverty persistence to the simulation exercise. As Table 8 shows, the same characteristics that reduce exit rates often increase re-entry rates. Note that, as exit rates are generally much higher than re-entry rates, the effect of any given covariate on total poverty persistence is dominated by the former.

\section{Duration dependence}

Our hazard rate models allow for a fully flexible non-parametric specification of the baseline hazard functions (Meyer, 1990) by including interval-specific dummies for the duration of the spell. By examining the coefficients of these interval-specific dummies in Table 8, it can 
be noted that the data broadly confirm the existence of negative duration dependence for the exit rates, as already suggested by the simple life-table estimates. Its importance and significance is somewhat reduced, given that we now control for many other economic and demographic factors, including unobserved heterogeneity. This is often the case in duration models and is generally taken as an indication that the duration dependence is at least partly due to sorting effects (those with favorable characteristics tend to leave earlier) rather than indicating "true state dependence”, e.g., a "scarring" effect due to depreciation of human capital or to deterioration of one's social network. Indeed, the duration dummies are jointly statistically significant for each poverty definition ${ }^{\text {xxiii }}$, although a few individual dummies are not. From an econometric point of view these findings highlight the importance of allowing for an unrestricted dynamics in models studying poverty persistence; therefore models assuming simpler, first-order Markov dynamics (e.g., Cappellari and Jenkins, 2002) may produce invalid inferences. Negative duration dependence is also found in the re-entry rates for IP. As the chances of returning into poverty decrease with time spent out of poverty, governments may find it effective to help those individuals that have recently managed to leave poverty_-job retentions policies, start-up grants, and continued income maintenance for the novel poverty escapers are examples of measures likely to produce long-lasting poverty reduction effects. Note, however, that evidence of duration dependence for re-entry rates in LSD mostly disappears after controlling for observed and unobserved heterogeneity.

We also investigate the effect of accumulated poverty and non-poverty on exit and re-entry rates from the current poverty and non-poverty spells. Dummy indicators indicating that the person had already experienced a poverty (non-poverty) spell in the past were included in the exit (re-entry) rate equations, but are always found to be statistically insignificant. A similar conclusion is reached when the number for past spells is included instead. Therefore, we find little evidence of a causal effect of earlier spells of poverty on current spells, and we suspect that this finding is related to the fact that we already control, quite flexibly, for much observed 
heterogeneity, for (correlated) unobserved heterogeneity and non-parametric duration dependence.

\section{Unobserved heterogeneity}

Unobserved heterogeneity is controlled for by making our hazard rates dependent on random intercepts specific to the type of spell $-\theta^{P}$ for poverty spells and $\theta^{N}$ for out-of-poverty spells. We allow for temporal correlation across spells of the same type, and also for correlation across spells of different types, by assuming that $\theta^{P}$ and $\theta^{N}$ are jointly distributed with CDF given by $G\left(\theta^{P}, \theta^{N}\right)$. Exit and re-entry rate models are estimated jointly using the Heckman and Singer (1984) estimator ${ }^{\text {xxiv }}$ (see the online Appendix for details). The estimated unobserved heterogeneity distribution is displayed in the final rows of Table 8. For each poverty definition, the data allowed only two support points, $\theta_{\text {low }}^{k}$ and $\theta_{\text {high }}^{k}$, for each of the individual-specific error terms, $k=P, N$.

The vast majority of individuals in the population, 91 percent, are estimated to have a high unobserved tendency to exit IP ( $\theta^{P}$ high, normalized to zero with no loss of generality) and a low tendency to re-enter $\left(\theta^{P}{ }_{\text {low }}<0\right)$. A small minority, however, the remaining 9 percent, have a higher than average persistence, with lower exit rates $\left(\theta^{P}{ }_{\text {low }}<0\right)$ and higher re-entry rates $\left(\theta^{N}{ }_{h i g h}\right.$, also normalized to zero). The data does not support the presence of the other combinations of unobserved heterogeneity terms (i.e., groups with $\left[\theta^{P}{ }_{\text {low }}, \theta^{N}{ }_{\text {low }}\right]$ and $\left[\theta^{P}{ }_{\text {high }}, \theta^{N}{ }_{\text {high }}\right]$, respectively), as the corresponding probabilities are estimated to be zero. ${ }^{\mathrm{xxv}}$ Note that the estimated support points are large $\left(\theta_{\text {low }}^{P}=-1.20\right.$ and $\left.\theta_{\text {low }}^{N}=-2.21\right)$, implying that the persistence in IP for the individuals who belong to the unlucky 9 percent is much longer than for the rest of the population. In fact, all other factors assumed equal, individuals in this group have an exit rate of approximately 91 percent lower and a re-entry rate 77 percent higher than the rest of the population. The unobserved heterogeneity distributions for LSD has similar features; the estimated support points and mass probabilities are fairly comparable in magnitude. Clearly, it is 
difficult for policy makers to target their interventions on these small but riskier groups, as by definition they are unobservable. The results here only suggest that there are factors, unobserved to analysts and policymakers, that make poverty a very persistent phenomenon, as well as a very challenging one.

\section{PREDICTED POVERTY PERSISTENCE}

The previous section suggested the existence of segments of the population whose members are likely to suffer from persistent poverty. This occurs because individuals who belong to these groups not only have lower exit rates than the rest of the population; they also tend to have higher re-entry rates. Therefore, to draw implications for the poverty persistence they experience, it is necessary to bring together information about their exit and re-entry rates to calculate the distribution of "time spent poor" over multiple spells. While this was already addressed in Section 6 with respect to a homogeneous population, we now provide estimates of poverty persistence for a number of selected sub-groups. To do so, we simulate the longitudinal poverty profiles of a large sample of poverty entrants (10,000 individuals) who are homogeneous in selected economic and demographic characteristics. The simulations use the variables and coefficients estimated in Table 8, including the estimated distribution of unobserved heterogeneity. The groups considered are formed by combining only the covariates that were broadly statistically significant in the models of Table 8; the remaining variables are set to their sample means. ${ }^{\text {xxvi }}$ The results are presented in Table 9. Note that the simulations refer to those who have just entered into poverty, therefore everyone is poor at least for one year by definition. While the simulations produce the entire distribution of the "number of years in poverty out of the next 7”, the table shows only two summary measures of persistence, in the interest of brevity: the expected number of years in poverty and the percentage of individuals who spend at least four years in poverty. As background information, we also report the group's likelihood of 
entering poverty, computed by estimating $\operatorname{Prob}$ (poor in year t $\mid$ not poor in t-1; X) from model 1 in Table 4.

In these simulations, the characteristics of the individual are held fixed throughout the simulation period, with the exception of age. The purpose here is to contrast, with the strongest possible force, the effect that certain characteristics might have on poverty persistence. For example, we may compare the predicted number of years in poverty for individuals whose spouse is out of work for the entire simulation period (8 years) with the prediction obtained for an individual whose spouse has always been in paid work, other factors assumed equal. Clearly, the simulation can be designed so as to contrast the poverty persistence arising in intermediate cases (for example, work for only half the period, or any number of years during the simulation period); the effect is simply bound to be smaller than in the previous case. We find that it is simpler to contrast these most extreme thought experiments, but intermediate cases are easily implemented within the methodology of the paper.

This discussion hinges on the role of "events" as opposed to "characteristics" in the empirical literature on poverty dynamics. Events (e.g., birth a child) are changes in the underlying characteristics (number of children in the household), and is clearly very difficult to identify the effects of events while controlling for characteristics at the beginning of the period (Jenkins, 2000, provides relevant discussion on this point). In fact, in our experience estimating dynamic models that include both an extensive set of characteristics and indicators for events generally results in statistically insignificant coefficients for the event indicators. Our empirical-compromise-choice has therefore been $(a)$ to estimate discrete-time duration models (Table 8) in which we allow covariates (e.g. the number of children) to be time-varying, without including events indicators directly, and $(b)$ to use the estimated coefficients of these time-varying characteristics to perform the kind of simulation exercises displayed in Table 9. In this case, the effect of "events" can still be accommodated in the simulation exercises; for example the effect of the "birth of a child in period 3" can be approximated by setting the 
number of children at 0 , for example, for simulation periods $t 1$ and $t 2$, and increase it to 1 for periods t3 and onward. Again, however, poverty persistence will be found to lie between the value obtained for the case with no children throughout the period and the value obtained for the simulation with 1 child for the whole period.

Consider first the case of a couple without children, in which the head of the household is aged 50, highly educated, normally employed and resides in the North of Italy (group A in Table 9). Individuals with these characteristics rarely fall in poverty: their entry probability is between 0.2 percent and 0.7percent, compared to 7percent probability for the whole population. Moreover, when they do fall below the poverty line, they do not tend to stay there long; the expected number of years below the poverty line is 1.59 for IP and 1.79 for LSD. Only 4 percent of these individuals will be poor for at least four out of the next seven years for IP and 7 percent for LSD.

We now take group A as a sort of base scenario, to which the rest of the rows in Table 9 add "risk factors" cumulatively, which will result in increased "entry probability” and longer persistence in poverty. Note that, in the base group, poverty persistence in LSD is higher than in IP. In light of the warnings given earlier regarding the non-comparability of the levels of poverty persistence across the two poverty definitions, our main aim in Table 9 is to investigate how far the two approaches are able to produce a consistent ranking of the population groups in terms of the risks of high poverty persistence that they face. Discussing how much the addition of risk factors changes the persistence with respect to the base scenario is also of interest, as it provides a convenient way of summarizing the differential impacts of the various sets of covariates on either form of poverty.

The next row (group B) depicts the situation of a person living in a household type as in group A, but where there are two children. The expected number of years in poverty is now estimated at 1.93 for IP and 1.91 for LSD. Note that the increase in IP persistence is larger than in LSD persistence. In the next row (group C), the spouse does not work and poverty persistence 
increases further, at 2.44 for IP, while for LSD the corresponding figure is 2.03. If additionally the head is not working (group D), the expected number of years in poverty rises to 3.23 for IP and to 2.26 for LSD. Group E shows the additional impact of living in a household whose head has low education; in this case the expected number of years in poverty is 4.13 for IP and 2.71 for LSD. The percentage of people with at least four years in poverty is 46 percent for IP, which is almost half that of LSD, at 22 percent.

Note that the addition of the risk factors considered above consistently raises IP persistence more than LSD persistence. As noted in Section 2, these findings suggest that the household is in part able to mitigate the negative impact of adverse labor market and demographic circumstances on its total income by resorting to a number of market and non-market coping strategies. Thus the use of accumulated wealth can sustain a household's standard of living when, say, its income is low due to non-participation in the labor market. Another possibility is to reduce the quality content (and therefore the value) of durable goods and other essential items purchased by the household. A low-income household can also escape deprivation within the 7-year period by receiving some of the durable goods as gifts from members of the local community, also as part of informal insurance mechanisms. In a country like Italy, the presence of an extensive network of solidarity, the enlarged family above all, may enable low-income households with children to sustain their standard of living. As noted earlier, these mechanisms would be captured by a consumption-based definition such as our LSD indicator, but not necessarily by an equivalent income-based definition.

The situation worsens still if the same household lives in the South of Italy (group F); in this case persistence is expected to be 5.82 years for IP and 4.05 for LSD. The percentage with at least four years in poverty is 78 percent for the first definition and 48 percent for the second. The increase in poverty persistence when moving from the North to the South of the country is considerable for both definitions, but somewhat lower in the case of LSD. As note earlier, this is consistent with the view that the lower prices of many goods and services in the South of the 
country may contribute to alleviating the territorial differences in the standards of living arising from large disparities in incomes. The persistence of poverty increases further if, in addition, the household head is young (aged 30 in group G). A worse situation is one of a young, single mother, aged 25, with three children, with low education, not working and living in the South. In this case, poverty is extremely persistent, ranging between 5.96 and 4.73 years, and with 81 to 61 percent of persons in such a household type spending at least four years below the line. It is tempting to relate, at least in part, the gravity of this situation to the absence of a universal instrument of public assistance, such as a minimum income guarantee.

Row I adds to the previous case the presence of an elderly person. This is found to significantly reduce the persistence of poverty when measured by equivalent income, perhaps reflecting additional income deriving from the pension of the elderly individual; however, persistence in LSD increases slightly, which may be related to a concomitant increase in the household's greater needs (e.g., health expenses of the elderly person). The worst scenario represented in the table is shown by row L, with a young head of household aged 30 as in case $\mathrm{G}$, who is unemployed instead of inactive. The increase in poverty persistence is sizeable for both definitions, and illustrates a paradoxical result of the Italian system of social protectioninactivity may be more conducive to poverty escapes than unemployment. The finding may arise from a combination of poorly-targeted public assistance programs for those out of the labor force and insufficient unemployment benefits for many categories of workers, above all young employees and those employed in the large number of small firms (Dell’Arringa, 2003).

The bottom panel of the table considers instead the poverty experience of elderly couples, usually regarded as a broad group at high risk of poverty and in need of special policy attention. Group M could represent the situation of an elderly couple, with no children, head aged 75, with high education, retired, spouse not working, and living in the North of Italy. Indeed, poverty in this case is not particularly persistent: 1.97 years for IP and 1.60 for LSD. However, the situation rapidly worsens as additional risk factors are added to the household environment. Therefore, if 
the head has low education and lives in the South (group O), persistence is now at 3.87 years for IP and 3.15 for LSD. The final two rows of the table show how persistent poverty is likely to be when additional non-working members are present in the household and the head is relatively old. If an inactive adult person is added, perhaps a disabled relative, and the head is aged 85 , the number of years in poverty for the two definitions is expected to be, respectively, 5.41 and 3.78 years, and the corresponding percentage of poor for at least four years is 71 percent and 43 percent.

Thus far the two definition of poverty persistence have produced a consistent ranking of the risks of poverty persistence faced by the various groups of the population. The final rows of the table show two cases in which the two definitions provide conflicting predictions. Row R reconsiders case B but assumes that the household head is now self-employed. Persistence in IP thus increases from 1.9 to 2.1, whereas persistence in LSD is reduced by 1.9 to 1.7. As noted above, it is tempting to relate this circumstance to the inability of the income definition to adequately capture the living standards of self-employed households due to income underreporting. The second example is shown in Row S, which re-considers case I but now adds a member with chronic health problems. This additional risk factor is correctly captured by LSD, for which persistence increases slightly, but not by IP.

\section{CONCLUSIONS}

This paper provided a first empirical assessment on the dynamics and persistence of poverty for individuals living in Italy during the 1990s. Poverty has been defined following two different approaches. The first approach defines poverty in terms of low income; the second, termed "life-style deprivation", defines poverty in terms of deprivation from a bundle of items for which possession is widespread in contemporaneous Italy. The results showed that poverty features a high degree of turnover: from one year to the next, a relatively large fraction of the Italian population enters into and exits from poverty. We found that these results are true for both 
definitions, increasing our confidence that frequent movements in and out of poverty are a fundamental feature of poverty.

Despite the fact that poverty appears to be rather transitory in general, there are groups of individuals who are likely to spend a higher number of years below the threshold than the rest of the population. To shed light on the identity of these groups, we estimated discrete-time multivariate hazard rate models, which allowed for unrestricted duration dependence and controlling for observed and correlated unobserved heterogeneity. Allowing for the latter was found to be important, as the estimates showed that individuals whose unobserved traits make them less able to escape poverty are also those with an (unobserved) high tendency to fall back in.

Our data generally revealed the existence of a negative relationship between hazard rates and the duration of the poverty spell. This implies that policies should be specifically addressed to the long-term poor, who are otherwise condemned to a spiral of persistent poverty and outright social exclusion. At the same time, the presence of negative duration dependence in the exit rates implies that timely policy interventions, if successful in promoting an early escape above the threshold, can have long-term effects on poverty reduction. Some evidence of negative duration dependence was also found for the re-entry rates, and therefore policies should be directed at preventing early re-entry.

We then used the model estimates to simulate the distribution of the number of years in poverty over multiple spells for selected groups of the population. People living in households with many children, with a head who is either very young or very old, and who has a low level of education constitute cases with higher risk of persistent poverty than the rest of the population. With large and statistically-significant coefficients for each poverty definition, the household's area of residence, the labor market status of the household head, and the number of working members other than the head were all found to be of crucial importance. This is not surprising 
for a country like Italy, characterized by a longstanding territorial dualism, with a stagnant and underdeveloped South, and a poorly performing labor market.

For Italy, perhaps more than elsewhere in Europe, we therefore emphasize the importance of policies aimed at increasing the presence of secondary income earners in the household in the context of complex strategies to combat poverty. Some examples that appear particularly appropriate to the Italian case include the extension of nursery schools and other fundamental social services, the promotion of part-time and other work arrangements suitable to the needs of young people, women and elderly individuals, a greater investment in re-training programs and access to new technologies, as well as changes in retirement rules and the elimination of a wide range of institutions reducing the incentive to labor market participation (e.g., Negri and Saraceno, 1996).

While the emphasis on labor market policies seems widely justified by the estimation results, the well-known limits of the Italian social security system also emerged, as reflected by the risks faced by specific groups of the population, above all those characterized by the presence in the household of children, elderly people or members unable to participate in the labor market for various reasons. Families and other long-established informal nets of community-level social assistance, which remain pillars of the country's social model, are often successful in mitigating the poverty generated in the labor market, but are nonetheless unable to fully counterbalance the inadequacies of the country's social policies. Recent tendencies of reform towards a rationalization of public expenses for social assistance, a more effective targeting of policy interventions, and overcoming the traditional sectoral logic in favor of a selective-universalistic approach appear to be promising directions for the future, as is the introduction of a long-awaited minimum income guarantee (Sacchi and Bastagli, 2005).

We offered theoretical arguments and empirical evidence suggesting that poverty and lifestyle deprivation offer two valid proxies of the longitudinal behavior of an underlying, unobserved notion of living standards deprivation. In fact, IP and LSD were shown to be 
correlated to one another, and also to indicators representing a household financial satisfaction and ability to make ends meet. At the same time, while the longitudinal behavior of the two measures is similar at an aggregate level, important differences between the two definitions were found with respect to the impact of an individual's labor market and demographic characteristics.

To begin with, the bulk of the evidence suggested that IP is more sensitive to shocks that hit a household than is life-style deprivation, which appears to be true for both labor market and demographic shocks. This is because shocks that change a household's total income, or its equivalence scale factor, largely have a "mechanical” effect on equivalent income. However, the household can resort to various “coping strategies”, most notably through the use of savings and borrowing, to reduce the impact of these shocks on its life style. A second difference relates to the ability of the two approaches to reflect the "needs" level of a household. While IP only recognizes "needs" explicitly incorporated in the equivalence scale, life-style deprivation has the potential to reflect a much larger range of "needs" and situations that affect a household's true standards of living. In our empirical application, an increase in household health needs was associated with an increased persistence of LSD but not of IP. A third difference emerged with respect to self-employment, a circumstance that was found to be associated with higher IP but lower life-style deprivation, suggesting that income might not provide a reliable welfare measure—or may fail to be accurately measured—for certain categories of individuals.

Overall, we stressed the ability of the two definitions to provide a generally consistent characterization of the poverty persistence risks faced by various population subgroups, but also the additional insights to be gained by analyzing the two definitions in parallel in a longitudinal context. In our view, the two definitions have the potential to complement each other, both in a cross-sectional and in a longitudinal context, and should be analyzed in parallel whenever possible. 


\section{REFERENCES}

Aassve A, Burgess S, Propper, C, Dickson M (2005) Modelling Poverty by Not Modelling Poverty: A Simultaneous Hazard Approach to the UK. ISER Working paper 2005 - 26

Addabbo T. (2000), “Poverty Dynamics: Analysis of Household Income in Italy”, Labor 14(1), 119-144.

Arranz JM and Cantò O (2010), "Measuring The Effect Of Spell Recurrence On Poverty Dynamics", UNU-WIDER working paper no. 2010/72.

Baldini M., Bosi P. and Toso S. (2002) “Targeting Welfare in Italia: Old Problems and Perspectives of Reform”, Fiscal Studies, 23, 1, pp. 51-75.

Bane, M.J. and Ellwood, D.T. (1986), "Slipping into and out of poverty: the dynamics of spells”, Journal of Human Resources, 21, pp 1-23.

Berthoud R., Bryan M, and Bardasi E. (2004) “The Dynamics of Deprivation: the relationship between income and material deprivation over time”, Department for Work and Pensions, London, ISBN: 18412372802004.

Biewen, M. (2006): Who are the chronic poor? An econometric analysis of chronic poverty in Germany, Research on Economic Inequality, Vol. 13, pp. 31 - 62

Brandolini A., P. Cipollone e P. Sestito (2002), "Earnings Dispersion, Low Pay and Household Poverty in Italy, 1977-1998", in D. Cohen, T. Piketty e G. Saint-Paul (a cura di), The Economics of Rising Inequalities, pp. 225-264. Oxford: Oxford University Press.

Brandolini, A. e Saraceno, C. 2007 (eds) Povertà e benessere. Una geografia delle disuguaglianze in Italia, Bologna, Il Mulino.

Breen R. and Moisio P. (2004) “Poverty Dynamics Corrected For Measurement Error”, Journal Of Economic Inequality 2: 171-191

Cantó Sanchez O (2002), “Climbing Out of Poverty, Falling Back In: Low Income Stability in Spain," Applied Economics, vol. 34(15), pps 1903-16.

Cantó Sanchez, O. (2003), Finding out the Routes to Escape Poverty: the relevance of demographic vs. labour market events in Spain, Review of Income and Wealth, Series 49, Number 4, December, pp: 569-589.

Cappellari L and Jenkins SP (2004), “Modelling Low Income Transitions”, Journal of Applied Econometrics, 19, 5, pp. 593-610.

D’Ambrosio C., Deutch J, and Silber J (2008) “Multidimensional Approaches to Poverty Measurement: An Empirical Analysis of Poverty in Belgium, France, Germany, Italy and Spain, based on the European Panel”, forthcoming in Applied Economics. 
Deaton A. and Muellbauer J. (1980), Economics and Consumer Behaviour, Cambridge University press.

Deaton A. (1992), Understanding Consumption, Oxford University Press

Dell’Arringa C. (2003), “The Italian Labor Market: Problems and Prospects”, Quaderni dell’Istituto di Economia dell'Impresa e del Lavoro, Università Cattolica del S. Cuore, Milan, n.33, pp. 1-35.

Deutsch J. and Silber J (2005). "Measuring Multidimensional Poverty: An empirical Comparison Of Various Approaches”, Review of Income and Wealth, 51, 1, 145-174.

Devicienti F (2002), "Poverty Persistence In Britain: A Multivariate Analysis Using The BHPS, 1991-1997”, Journal Of Economics, Suppl. 9: 1-34.

Devicienti F (2011), “Estimating Poverty Persistence in Britain”, Empirical Economics (DOI: 10.1007/s00181-010-0350-2).

European Commission (2002) "Employment in Europe. Recent Trends and Prospects", Luxembourg: Office for Official Publication of the European Communities.

Ferrera M. (2005) "Welfare State Reform in Southern Europe. Fighting Poverty and Social Exclusion in Italy, Portugal and Greece”, (eds.), Routledge, London.

Giraldo A., Rettore E. and Trivellato U. (2002) “The Persistence Of Poverty: True State Dependence or Unobserved Heterogeneity? Some Evidence form The Italian Survey on Household Income and Wealth”, Working Paper, Dip. Scienze Statistiche, Università di Padova.

Heckman, J.J. and Singer, B. (1984) “A method for minimizing the impact of distributional assumptions in econometric models for duration data”; Econometrica, 52, 271- 320.

Jarvis, S. and Jenkins, S.P. (1997), “Low income dynamics in 1990s Britain”, Fiscal Studies, 18, pp 1-20.

Jenkins, S.P. (2000) “Modelling Household Income Dynamics”, Journal Of Population Economics, 13 (4).

Jenkins, S.P., Rigg, J., Devicienti F. (2001), The Dynamics of Poverty in Britain, Department for Work and Pensions, Research Report No 157, London.

Lee N, Ridder G and Strauss J (2009) "Estimation of Poverty Transition Matrices with Noisy Data", manuscript.

Meyer, B.D. (1990), “Unemployment insurance and unemployment spells”, Econometrica, 58(4), 757-782.

Modigliani, F. and R. H. Brumberg, 1954, "Utility analysis and the consumption function: an interpretation of cross-section data," in Kenneth K. Kurihara, ed., Post-Keynesian Economics, New Brunswick, NJ. Rutgers University Press. Pp 388-436. 
Muffels R and Fourage D (2004), "The Role of European Welfare States in Explaining Resources Deprivation." Social Indicators Research 68: 299-330.

Negri N. e Saraceno C. (1996) Le Politiche Contro la Povertà, Il Mulino. Bologna.

OECD (1998), "Low-income dynamics in four OECD countries”, OECD Economic Outlook, chapter VI, 171-185.

OECD (2001), "When Money is Tight: Poverty Dynamics in OECD Countries”, chap. 2 in Employment Outlook, Paris.

Peracchi F., "The European Community Household Panel: A Review", Empirical Economics, 27 (2002), 63-90.

Perry, B. (2002) “ The mismatch between income measures and direct outcome measures of poverty”, Social Policy Journal of New Zealand, 19, pp. 101-127.

Prentice, R. and Gloecker, L. (1978), "Regression analysis of grouped survival data with application to breast cancer data”, Biometrics, 34, pp 57-67.

Sacchi S. and Bastagli F. (2005), "Italy - Striving Uphill But Stopping Halfway: The Troubled Journey of the Experimental Minimum Insertion Income”, in Ferrera M. (eds.) "Welfare State Reform in Southern Europe. Fighting Poverty and Social Exclusion in Italy, Portugal and Greece”, Routledge, London.

Stevens AH (1999) “Climbing Out Of Poverty, Falling Back In: Measuring The Persistence Of Poverty Over Multiple Spells”. Journal Of Human Resources: XXXIV, (34)3: 557-588.

Sen, A.K. (1985), Commodities and Capabilities, Oxford University Press, Oxford.

Utili F. and Rostagno M. (1998) “The Italian Social Protection System: The Poverty of Welfare”, IMF Working Paper, WP/98/74.

Valletta R.G. (2006), “The Ins and Outs of Poverty in Advanced Economics: Government Policies and Poverty Dynamics in Canada, Germany, Great Britain and the United States”, Review of Income and Wealth, 52(2), pp. 261-284.

Townsend (1979), “Poverty in the United Kingdom, a Survey of Household Resources and Standard of living”, London, Penguin Books and Allen Lane.

Whelan, C.T., Layte, R., and Maitre, B. (2004) "Understanding the Mismatch between income poverty and deprivation: a dynamic comparative analysis”, European Sociological Review, Vol. 20, pp.287-302.

Whelan C.T. and Maitre B. (2006) "Comparing Poverty and Deprivation Dynamics: Issues of Reliability and Validity”, The Journal of Economic Inequality, 4: 303-323. 
Tables and comments

Table 1: Cross-Sectional Poverty Incidence, 1994-2001

\begin{tabular}{|c|c|c|c|c|c|c|c|c|c|}
\hline & 1994 & 1995 & 1996 & 1997 & 1998 & 1999 & 2000 & 2001 & Average \\
\hline \multicolumn{10}{|l|}{ income poverty } \\
\hline threshold fixed in real terms & 20.4 & 20.1 & 18.8 & 17.1 & 14.7 & 13.6 & 12.5 & 13.0 & 16.5 \\
\hline threshold time-varying & 20.4 & 20.4 & 20.1 & 19.5 & 18.0 & 18.0 & 18.4 & 19.3 & 19.3 \\
\hline \multicolumn{10}{|l|}{ Life-style deprivation } \\
\hline threshold at $70 \%$ median S score & 11.1 & 11.9 & 9.8 & 8.0 & 7.3 & 6.8 & 6.7 & 6.8 & 8.7 \\
\hline threshold at $80 \%$ median S score & 18.7 & 18.3 & 15.8 & 14.4 & 13.7 & 12.5 & 11.6 & 10.7 & 15.0 \\
\hline Number of individuals & 21396 & 21423 & 21224 & 19861 & 19141 & 18449 & 17516 & 16014 & \\
\hline
\end{tabular}

Notes: Unbalanced sample of persons (adults and children) in complete respondent households for all waves for which they are in the sample. ECHP cross-sectional weights have been used.

Table 2. Percentage of individuals in poverty for $x$ years

\begin{tabular}{lccccccccc}
\multicolumn{1}{c}{ Number of years in poverty: } & $\mathbf{0}$ & $\mathbf{1}$ & $\mathbf{2}$ & $\mathbf{3}$ & $\mathbf{4}$ & $\mathbf{5}$ & $\mathbf{6}$ & $\mathbf{7}$ & $\mathbf{8}$ \\
\hline $\begin{array}{l}\text { Income poverty } \\
\text { threshold fixed in real terms }\end{array}$ & 56.4 & 13.4 & 7.6 & 5.3 & 4.5 & 4.2 & 3.0 & 3.4 & 2.3 \\
threshold time-varying & 51.7 & 13.1 & 7.7 & 6.5 & 4.9 & 4.8 & 4.0 & 4.1 & 3.3 \\
\hline $\begin{array}{l}\text { Life-style deprivation } \\
\text { threshold at 70\% median S score }\end{array}$ & 71.4 & 12.5 & 5.5 & 3.2 & 2.4 & 1.7 & 1.1 & 1.3 & 0.9 \\
\begin{tabular}{l} 
threshold at 80\% median S score \\
\hline \hline
\end{tabular} & 58.0 & 14.6 & 7.9 & 5.5 & 4.1 & 3.1 & 2.5 & 2.1 & 2.3 \\
\hline
\end{tabular}

Notes: Balanced longitudinal sample. 
Table 3: The determinants of income poverty and life-style deprivation. Probit models

\begin{tabular}{|c|c|c|c|c|c|c|c|c|}
\hline & \multicolumn{2}{|c|}{ (1) } & \multicolumn{2}{|c|}{ (2) } & \multicolumn{2}{|c|}{ (3) } & \multicolumn{2}{|c|}{ (4) } \\
\hline & \multicolumn{2}{|c|}{ Currently Income poor } & \multicolumn{2}{|c|}{$\begin{array}{c}\text { Currently } \\
\text { Life-style deprived }\end{array}$} & \multicolumn{2}{|c|}{ Persistently income poor } & \multicolumn{2}{|c|}{$\begin{array}{c}\text { Persistently life-style } \\
\text { deprived }\end{array}$} \\
\hline & Marg. effect & s.e. & Marg. effect & s.e. & Marg. effect & s.e. & Marg. effect & s.e. \\
\hline number of children & $0.03754^{* * *}$ & 0.00107 & $0.01782^{* * *}$ & 0.00094 & $0.00616^{* * *}$ & 0.00085 & $0.00204^{* * *}$ & 0.00065 \\
\hline no. persons aged 18-64 & $0.04839 * * *$ & 0.00097 & $0.01951 * * *$ & 0.00083 & $0.00533 * * *$ & 0.0008 & $0.00251^{* * *}$ & 0.00057 \\
\hline no. persons aged 65+ & -0.00326 & 0.00229 & $0.00370^{*}$ & 0.002 & 0.00062 & 0.00181 & -0.00446 & 0.00433 \\
\hline no. of workers & $-0.09250 * * *$ & 0.00133 & $-0.03029 * * *$ & 0.00111 & $-0.01627 * * *$ & 0.00153 & $-0.00606 * * *$ & 0.00092 \\
\hline Child & 0.00243 & 0.00242 & -0.00186 & 0.00213 & 0.00095 & 0.00186 & -0.00022 & 0.00148 \\
\hline Old & $0.01584 * * *$ & 0.0038 & 0.00022 & 0.00311 & 0.00019 & 0.00258 & -0.00065 & 0.00182 \\
\hline Female & $0.00428 * * *$ & 0.00166 & -0.00005 & 0.00148 & -0.00091 & 0.00127 & -0.00036 & 0.001 \\
\hline age of hh head & $-0.00390 * * *$ & 0.00045 & $-0.00404 * * *$ & 0.00039 & 0.00036 & 0.00037 & $-0.00063 * *$ & 0.00026 \\
\hline age of hh head squared & $0.00004 * * *$ & 0.00001 & $0.00003 * * *$ & 0.00001 & $-1.81 \mathrm{e}-06$ & $3.54 \mathrm{e}-06$ & $0.00001^{* * *}$ & $2.51 \mathrm{e}-06$ \\
\hline female hh head & $0.02654 * * *$ & 0.00346 & $0.02392 * * *$ & 0.003 & $0.01225 * * *$ & 0.00394 & 0.00342 & 0.00219 \\
\hline Head has low education & $0.08628 * * *$ & 0.00181 & $0.05965 * * *$ & 0.00163 & $0.02452 * * *$ & 0.00233 & $0.01169 * * *$ & 0.00159 \\
\hline Head has high education & $-0.04411^{* * *}$ & 0.00309 & $-0.03681^{* * *}$ & 0.00272 & -0.00042 & 0.00499 & 0.00214 & 0.00446 \\
\hline Head working $<15$ hours & $0.16768 * * *$ & 0.014 & $0.15373 * * *$ & 0.01264 & $0.04138 * *$ & 0.01994 & $0.08744 * * *$ & 0.03003 \\
\hline Unemployed head & $0.37868 * * *$ & 0.00967 & $0.18195 * * *$ & 0.00725 & $0.04750 * * *$ & 0.00969 & $0.06995 * * *$ & 0.01258 \\
\hline Discouraged head & $0.32320 * * *$ & 0.02138 & $0.11227 * * *$ & 0.0147 & 0.00351 & 0.00953 & $0.06044 * *$ & 0.02411 \\
\hline Inactive head & $0.09384 * * *$ & 0.00342 & $0.01938 * * *$ & 0.00255 & $0.01157 * * *$ & 0.00284 & $0.00856 * * *$ & 0.00225 \\
\hline North & $-0.02574 * * *$ & 0.00238 & $-0.02606 * * *$ & 0.00213 & $-0.00822 * * *$ & 0.00217 & -0.00033 & 0.00196 \\
\hline South & $0.09168 * * *$ & 0.0027 & $0.07395 * * *$ & 0.00242 & $0.01827 * * *$ & 0.00285 & $0.01492 * * *$ & 0.00278 \\
\hline $\begin{array}{l}\text { No. health problems in } \\
\text { the hh }\end{array}$ & -0.00237 & 0.00154 & $0.02242 * * *$ & 0.0013 & $-0.00240 * *$ & 0.00109 & $0.00364 * * *$ & 0.00081 \\
\hline Separated/divorced head & $0.03700 * * *$ & 0.0045 & $0.02632 * * *$ & 0.00383 & 0.00283 & 0.00332 & 0.00181 & 0.0024 \\
\hline Single head & $0.04583 * * *$ & 0.00528 & $0.03503 * * *$ & 0.00445 & 0.00417 & 0.00424 & 0.00451 & 0.00342 \\
\hline Single parent head & $0.03470 * * *$ & 0.00898 & $0.01829 * *$ & 0.00724 & $-0.00939 * * *$ & 0.00181 & 0.00513 & 0.00668 \\
\hline $\begin{array}{l}\text { Self employed head } \\
\text { Const }\end{array}$ & $0.11437 * * *$ & 0.00316 & $-0.02115^{* * *}$ & 0.00185 & $0.01226 * * *$ & 0.00294 & $-0.00494 * * *$ & 0.00127 \\
\hline No. observations & 126473 & & 127889 & & 14831 & & 14831 & \\
\hline
\end{tabular}

Notes: Probit estimates. Pooled w1-w8 sample in model 1 and 2. Persistently deprived or poor are those deprived or poor for at least 4 consecutive waves. For model 3 and 4 the longitudinal sample is unbalanced and includes individuals present in $t, t+1, t+2 t+3$, where $t=$ wave 5 , wave 4 or wave 3 . Covariates refer to year t. 
Table 4: The association between deprivation and income poverty

\begin{tabular}{|c|c|c|c|c|c|c|c|c|c|c|}
\hline & \multicolumn{2}{|c|}{$(1)$} & \multicolumn{2}{|c|}{$(2)$} & \multicolumn{2}{|c|}{$(3)$} & \multicolumn{2}{|c|}{$(4)$} & \multicolumn{2}{|c|}{ (5) } \\
\hline & \multicolumn{8}{|c|}{ Probit models } & \multicolumn{2}{|c|}{ OLS } \\
\hline & & Life-s & style deprivatic & $\mathrm{n}$ in $\mathrm{t}$ & & & $\begin{array}{r}\text { Deprivatic } \\
\text { consec }\end{array}$ & $\begin{array}{l}\text { at least } 4 \\
\text { years }\end{array}$ & $\begin{array}{r}\text { No. of year } \\
\text { depri }\end{array}$ & $\begin{array}{l}\text { life-style } \\
\text { tion }\end{array}$ \\
\hline & $\begin{array}{l}\text { Marginal } \\
\text { effect }\end{array}$ & s.e. & $\begin{array}{l}\text { Marginal } \\
\text { effect }\end{array}$ & s.e. & $\begin{array}{l}\text { Marginal } \\
\text { effect }\end{array}$ & s.e. & $\begin{array}{l}\text { Marginal } \\
\text { effect }\end{array}$ & s.e. & Coeff. & s.e. \\
\hline Poor in $t$ & $0.09975^{* * *}$ & 0.00302 & $0.02787 * * *$ & 0.00351 & $0.02444 * * *$ & 0.00492 & & & & \\
\hline poor in $\mathrm{t}-1$ & & & $0.03529 * * *$ & 0.00374 & $0.02236 * * *$ & 0.00497 & & & & \\
\hline poor in $\mathrm{t}-2$ & & & $0.02424 * * *$ & 0.00335 & $0.02172 * * *$ & 0.00478 & & & & \\
\hline poor in $\mathrm{t}-3$ & & & $0.02936 * * *$ & 0.00317 & $0.02899 * * *$ & 0.00482 & & & & \\
\hline poor in $\mathrm{t}-4$ & & & & & $0.01055^{* * *}$ & 0.004 & & & & \\
\hline poor in $\mathrm{t}-5$ & & & & & $0.01150^{* * *}$ & 0.0037 & & & & \\
\hline $\begin{array}{l}\text { Poor at least } 4 \text { consecutive } \\
\text { years }\end{array}$ & & & & & & & $0.08985^{* * *}$ & 0.01018 & & \\
\hline No. of years in poverty & & & & & & & & & $0.28051^{* * *}$ & 0.00792 \\
\hline
\end{tabular}

Notes: All regressions include a full list of controls (as in Tables 4). Probit marginal effects for models (1)-(5). OLS estimates for model (6). Pooled w1-w8 sample for models (1)-(3).

Model (4) is based on all individuals observed in each wave between w5-w8, or between w4-w7 or between w3-w7. Controls in model (5) refer to the initial year (w5 or w4 or w3).

Model (5) is based on all individuals observed in each of the 8 waves (w1-w8); controls in this case refer to w1. 
Table 5: The association between financial satisfaction, the ability of make ends meet and poverty

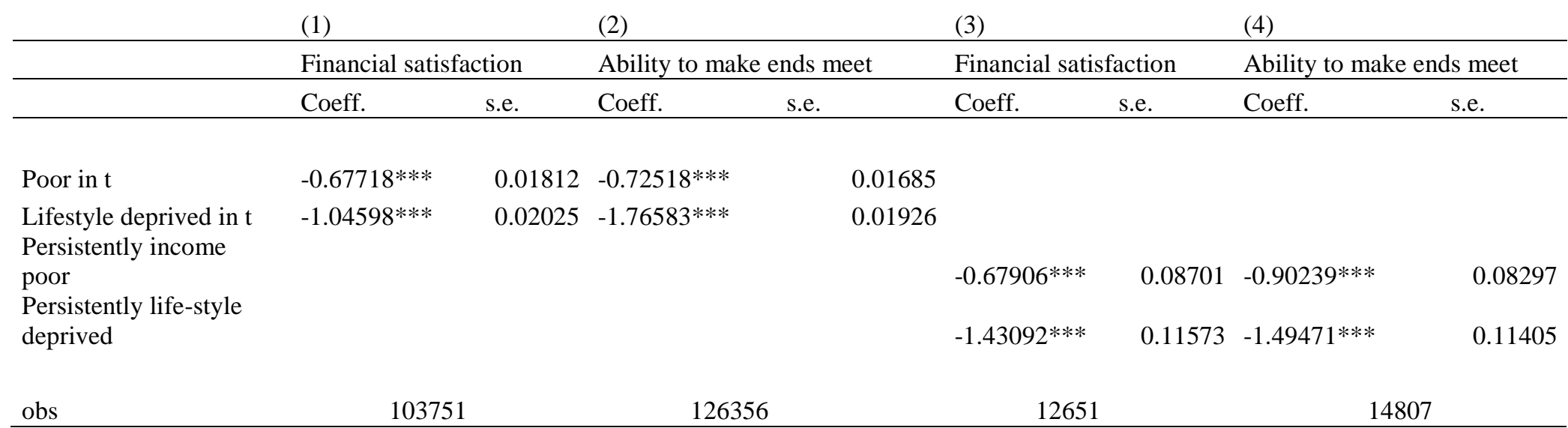

Notes: All regressions include a full list of controls (as in Tables 4). Ordered logit estimates. Pooled w1-w8 sample for models (1)-(2). Model (3) and (4) are based on all individuals observed in each wave between w5-w8, or between w4-w7 or between w3-w7. Controls refer to the initial year (w5 or w4 or w3). Persistent

poverty is defined as income poor for at least 4 consecutive years. Persistent life-style deprivation is defined as life-style deprived for at least 4 consecutive years. 


\section{Table 6: Survivor Functions And Hazard Rates Exit Rates From Poverty (Kaplan-Meier Estimates)}

\begin{tabular}{|c|c|c|c|c|c|c|c|c|c|c|c|c|}
\hline & \multicolumn{6}{|c|}{ Exit rates } & \multicolumn{6}{|c|}{ re-entry rates } \\
\hline & \multirow{2}{*}{\multicolumn{2}{|c|}{ Income poverty }} & \multirow{2}{*}{\multicolumn{4}{|c|}{\begin{tabular}{ll}
\multicolumn{2}{c}{ Life style deprivation } \\
$70 \%$ threshold & $80 \%$ threshold
\end{tabular}}} & \multirow{2}{*}{\multicolumn{2}{|c|}{ Income poverty }} & \multicolumn{4}{|c|}{ Life style deprivation } \\
\hline & & & & & & & & & \multicolumn{2}{|c|}{$70 \%$ threshold } & \multicolumn{2}{|c|}{$80 \%$ threshold } \\
\hline $\begin{array}{l}\text { interviews } \\
\text { since start } \\
\text { of spell }\end{array}$ & $\begin{array}{l}\text { Survivor } \\
\text { function } \\
\text { (s.e.) }\end{array}$ & $\begin{array}{l}\text { Exit rates } \\
\text { (s.e.) }\end{array}$ & $\begin{array}{l}\text { Survivor } \\
\text { function } \\
\text { (s.e.) }\end{array}$ & $\begin{array}{l}\text { Exit rates } \\
\text { (s.e.) }\end{array}$ & $\begin{array}{l}\text { Survivor } \\
\text { function } \\
\text { (s.e.) }\end{array}$ & $\begin{array}{l}\text { Exit rates } \\
\text { (s.e.) }\end{array}$ & $\begin{array}{l}\text { Survivor } \\
\text { function } \\
\text { (s.e.) }\end{array}$ & $\begin{array}{l}\text { Exit rates } \\
\text { (s.e.) }\end{array}$ & $\begin{array}{l}\text { Survivor } \\
\text { function } \\
\text { (s.e.) }\end{array}$ & $\begin{array}{l}\text { Exit rates } \\
\text { (s.e.) }\end{array}$ & $\begin{array}{l}\text { Survivor } \\
\text { function } \\
\text { (s.e.) }\end{array}$ & $\begin{array}{l}\text { Exit rates } \\
\text { (s.e.) }\end{array}$ \\
\hline \multirow[t]{2}{*}{1} & 1.00 & ( & 1.00 & ( & 1.00 & (" & 1.00 & " & 1.00 & . & 1.00 & ( \\
\hline & $\cdot$ & $\cdot$ & $\cdot$ & . & $\cdot$ & . & . & • & . & . & $\cdot$ & $\cdot$ \\
\hline \multirow[t]{2}{*}{2} & 0.42 & 0.58 & 0.39 & 0.60 & 0.40 & 0.60 & 0.75 & 0.25 & 0.78 & 0.22 & 0.75 & 0.25 \\
\hline & $(0.007)$ & $-0.01)$ & $(0.0077)$ & $(0.0123)$ & $(0.01)$ & $(0.01)$ & $(0.005)$ & $(0.006)$ & $(0.006)$ & $(0.0068)$ & $(0.01)$ & $(0.01)$ \\
\hline \multirow[t]{2}{*}{3} & 0.23 & 0.46 & 0.22 & 0.46 & 0.24 & 0.40 & 0.64 & 0.15 & 0.69 & 0.12 & 0.63 & 0.16 \\
\hline & $(0.006)$ & $(0.016)$ & $(0.0069)$ & $(0.0182)$ & $(0.01)$ & $(0.01)$ & $(0.006)$ & $(0.006)$ & $(0.007)$ & $(0.0063)$ & $(0.01)$ & $(0.01)$ \\
\hline \multirow[t]{2}{*}{4} & 0.16 & 0.29 & 0.13 & 0.42 & 0.16 & 0.35 & 0.57 & 0.11 & 0.63 & 0.08 & 0.57 & 0.10 \\
\hline & $(0.006)$ & $(0.02)$ & $(0.006)$ & $(0.0266)$ & $(0.01)$ & $(0.02)$ & $(0.007)$ & $(0.006)$ & (0.0075) & $(0.006)$ & $(0.01)$ & $(0.01)$ \\
\hline 5 & 0.12 & 0.29 & 0.1 & 0.22 & 0.11 & 0.28 & 0.54 & 0.07 & 0.61 & 0.04 & 0.53 & 0.07 \\
\hline \multirow[t]{2}{*}{6} & 0.09 & 0.2 & 0.08 & 0.19 & 0.08 & 0.25 & 0.51 & 0.05 & 0.57 & 0.07 & 0.49 & 0.08 \\
\hline & $(0.006)$ & $(0.031)$ & $(0.0056)$ & $(0.0357)$ & $(0.00)$ & $(0.03)$ & $(0.008)$ & $(0.007)$ & (0.0088) & $(0.0082)$ & $(0.01)$ & $(0.01)$ \\
\hline \multirow[t]{2}{*}{7} & 0.07 & 0.22 & 0.06 & 0.19 & 0.06 & 0.28 & 0.49 & 0.04 & 0.55 & 0.04 & 0.47 & 0.04 \\
\hline & $(0.006)$ & $(0.051)$ & $(0.0057)$ & $(0.0482)$ & $(0.00)$ & $(0.05)$ & $(0.008)$ & $(0.008)$ & $(0.0098)$ & $(0.0088)$ & $0.01)$ & $(0.01)$ \\
\hline
\end{tabular}

Notes: Life table estimates based on all non-left censored spells, pooled from the ECHP waves 1-8. The number of individuals starting a poverty spell is 6095 for income poverty and 4008 for life-style deprivation (6030 with the $80 \%$ threshold). The number of individuals starting an out-of-poverty spell is 6749 for income poverty and 4703 for life-style deprivation (7085 with the $80 \%$ threshold). Standard errors in parenthesis. 
Table 7: Distribution Of The 'Number Of Interviews In Poverty Out Of The Next Seven'

\begin{tabular}{l|cc|cc}
\hline \hline $\begin{array}{l}\text { Number of interviews in } \\
\text { poverty out of the next } \\
\text { seven }\end{array}$ & \multicolumn{2}{|c|}{ Income poverty } & \multicolumn{2}{c}{ Life-style derivation } \\
& $\begin{array}{c}50 \% \\
\text { Threshold }\end{array}$ & $\begin{array}{c}60 \% \\
\text { Threshold }\end{array}$ & $\begin{array}{c}70 \% \\
\text { Threshold }\end{array}$ & $\begin{array}{c}80 \% \\
\text { Threshold }\end{array}$ \\
\hline \hline 1 & 33.4 & 29.3 & 34.3 & 29.1 \\
2 & 23.4 & 22.0 & 23.1 & 21.9 \\
3 & 16.3 & 15.9 & 15.7 & 16.3 \\
4 & 10.9 & 11.8 & 9.9 & 12.0 \\
5 & 6.7 & 7.8 & 6.1 & 8.5 \\
6 & 6.4 & 5.9 & 4.4 & 6.2 \\
7 & 2.9 & 7.3 & 6.5 & 6.1 \\
\hline $\begin{array}{l}\text { Expected numbed of } \\
\text { years in poverty }\end{array}$ & 2.6 & 2.9 & 2.7 & 2.9 \\
\hline $\begin{array}{l}\text { \% of individuals poor for } \\
\text { at least 4 years }\end{array}$ & 26.8 & 32.8 & 26.9 & 32.8 \\
\hline \hline
\end{tabular}

Notes: multiple spell methodology. 
Table 8: Multivariate analysis of exit and re-entry rates

\begin{tabular}{|c|c|c|c|c|c|c|c|c|}
\hline \multirow[b]{3}{*}{ Covariates } & \multicolumn{4}{|c|}{ Exit rates } & \multicolumn{4}{|c|}{ Re-entry rates } \\
\hline & \multicolumn{2}{|c|}{ Income poverty } & \multicolumn{2}{|c|}{ Life-style deprivation } & \multicolumn{2}{|c|}{ Income poverty } & \multicolumn{2}{|c|}{ Life-style deprivation } \\
\hline & coef & s.e. & coef & s.e. & coef & s.e. & coef & s.e. \\
\hline $1^{\text {st }}$ year in the spell & -0.340 & 0.303 & -0.155 & 0.276 & -1.399 & $0.476^{* *}$ & -0.267 & 0.539 \\
\hline $2^{\text {nd }}$ year in the spell & -0.563 & $0.308^{*}$ & -0.524 & $0.282^{* *}$ & -1.815 & $0.481 * * *$ & -0.658 & 0.552 \\
\hline $3^{\text {rd }}$ year in the spell & -1.092 & $0.316^{* * *}$ & -0.486 & $0.288 *$ & -1.906 & $0.482 * * *$ & -1.026 & $0.555^{*}$ \\
\hline $4^{\text {th }}$ year in the spell & -1.041 & $0.328 * * *$ & -0.757 & $0.308^{* *}$ & -2.355 & $0.485 * * *$ & -1.294 & $0.560 * *$ \\
\hline $5^{\text {th }}$ year in the spell & -1.744 & $0.384 * * *$ & -0.275 & 0.338 & -2.580 & $0.497 * * *$ & -1.855 & $0.576^{* * *}$ \\
\hline $6^{\text {th }}$ year in the spell & -1.584 & $0.440 * * *$ & -0.415 & 0.404 & -3.211 & $0.543 * * *$ & -1.257 & $0.585^{* *}$ \\
\hline number of children & -0.148 & $0.023 * * *$ & -0.058 & $0.028 * *$ & 0.328 & $0.026^{* * *}$ & 0.098 & $0.035 * *$ \\
\hline no. persons aged 18-64 & -0.109 & $0.023 * * *$ & -0.100 & $0.021 * * *$ & 0.328 & $0.030 * * *$ & 0.183 & $0.026^{* * *}$ \\
\hline no. persons aged 65+ & 0.267 & $0.059 * * *$ & 0.010 & 0.054 & -0.068 & 0.072 & -0.029 & 0.064 \\
\hline no. of workers & 0.324 & $0.033^{* * *}$ & 0.112 & $0.030 * * *$ & -0.676 & $0.043^{* * *}$ & -0.154 & $0.039 * * *$ \\
\hline Child & -0.050 & 0.056 & 0.000 & 0.059 & 0.083 & 0.071 & -0.004 & 0.075 \\
\hline Old & -0.113 & 0.093 & -0.019 & 0.085 & -0.098 & 0.114 & 0.226 & $0.101 * *$ \\
\hline Female & -0.082 & $0.041^{* *}$ & 0.023 & 0.041 & 0.066 & 0.052 & -0.021 & 0.050 \\
\hline age of hh head / 100 & 0.051 & $0.012 * * *$ & 0.025 & $0.011^{* *}$ & 0.003 & 0.016 & -0.038 & $0.013 * *$ \\
\hline age of hh head squared / 1000 & -0.001 & $0.000 * * *$ & -0.000 & $0.000 * *$ & 0.0001 & 0.0001 & 0.000 & $0.000 * * *$ \\
\hline female hh head & 0.094 & 0.077 & 0.064 & 0.069 & 0.366 & $0.092 * * *$ & 0.028 & 0.090 \\
\hline low education of hh head & -0.290 & $0.054 * * *$ & -0.254 & $0.055 * * *$ & 0.254 & $0.070 * * *$ & 0.356 & $0.075^{* * *}$ \\
\hline high education of hh head & 0.034 & 0.119 & 0.358 & 0.344 & -0.558 & $0.197 * *$ & 0.097 & 0.183 \\
\hline hh head working $<15$ hours & -0.418 & $0.168 * * *$ & -0.705 & $0.203 * * *$ & 0.478 & $0.254 * *$ & 0.598 & $0.207 * *$ \\
\hline Unemployed hh head & -0.739 & $0.092 * * *$ & -0.498 & $0.079 * * *$ & 1.052 & $0.111^{* * *}$ & 0.719 & $0.093 * * *$ \\
\hline Discouraged hh head & -1.162 & $0.235 * * *$ & -0.201 & 0.166 & 0.623 & $0.221^{* *}$ & 0.424 & $0.227^{*}$ \\
\hline Inactive hh head & -0.336 & $0.068 * * *$ & -0.168 & $0.064^{* *}$ & 0.352 & $0.087 * * *$ & 0.074 & 0.084 \\
\hline Hh is self employed & -0.133 & $0.054 * *$ & 0.186 & $0.062 * *$ & 0.269 & $0.067 * * *$ & 0.168 & $0.074 * *$ \\
\hline North & 0.136 & $0.062 * *$ & 0.281 & $0.072 * * *$ & -0.096 & 0.090 & -0.121 & 0.099 \\
\hline South & -0.369 & 0.054 & -0.200 & $0.061 * * *$ & 0.442 & $0.074 * * *$ & 0.611 & $0.080 * * *$ \\
\hline No. health problem in the hh & 0.040 & 0.038 & -0.016 & 0.032 & -0.015 & 0.044 & 0.081 & $0.039 * *$ \\
\hline Separated/divorced & 0.125 & 0.094 & -0.152 & $0.087 *$ & -0.133 & 0.116 & -0.059 & 0.112 \\
\hline Single & 0.031 & 0.104 & -0.138 & 0.096 & 0.107 & 0.153 & 0.226 & $0.125^{*}$ \\
\hline Single parent & -0.152 & 0.165 & -0.002 & 0.182 & 0.202 & 0.219 & 0.199 & 0.245 \\
\hline \multicolumn{9}{|l|}{$\begin{array}{l}\text { Unobserved heterogeneity } \\
\text { distribution }\end{array}$} \\
\hline Mass points: $\theta_{\text {low }}$ & -1.125 & $0.151 * * *$ & -1.796 & $0.257 * * *$ & -2.347 & $0.232 * * *$ & -2.125 & $0.400 * * *$ \\
\hline$\theta_{\text {high }}$ & $0^{*}$ & . & $0 *$ & . & $0^{*}$ & . & $0^{*}$ & $\cdot$ \\
\hline \multicolumn{9}{|l|}{ Mass probabilities: } \\
\hline $\operatorname{Prob}\left(\theta_{\text {low }}^{P}, \theta_{\text {low }}^{N}\right)$ & $0 *$ & . & & & $0 *$ & . & & \\
\hline $\operatorname{Prob}\left(\theta_{\text {high }}^{P}, \theta_{\text {low }}^{N}\right)$ & 0.94 & $0.024 * * *$ & 0.96 & $0.012 * * *$ & & & & \\
\hline $\operatorname{Prob}\left(\theta_{\text {high }}^{P}, \theta_{\text {high }}^{N}\right)$ & $0^{*}$ & . & $0^{*}$ & . & & & & \\
\hline $\operatorname{Prob}\left(\theta_{\text {low }}^{P}, \theta_{\text {high }}^{N}\right)$ & 0.06 & $0.024 * * *$ & 0.04 & $0.012^{* * *}$ & & & & \\
\hline Number of observations & 13920 & & 19071 & & & & & \\
\hline Log likelihood & -5651 & & -8812 & & & & & \\
\hline
\end{tabular}


Table 9: Estimated persistence in poverty: selected subgroups of the population

\begin{tabular}{|c|c|c|c|c|c|c|c|}
\hline & \multirow[b]{2}{*}{ Group } & \multicolumn{3}{|c|}{ Income poverty } & \multicolumn{3}{|c|}{ Life-style deprivation } \\
\hline & & $\begin{array}{c}\text { Entry } \\
\text { probability }\end{array}$ & $\begin{array}{l}\text { Mean number of } \\
\text { years in poverty }\end{array}$ & $\begin{array}{l}\text { \% with at least } 4 \\
\text { years in poverty }\end{array}$ & $\begin{array}{c}\text { Entry } \\
\text { probability }\end{array}$ & $\begin{array}{l}\text { Mean number of } \\
\text { years in poverty }\end{array}$ & $\begin{array}{l}\% \text { with at least } 4 \\
\text { years in poverty }\end{array}$ \\
\hline & All persons & 0.067 & 2.9 & 0.33 & 0.069 & 2.9 & 0.33 \\
\hline A & $\begin{array}{l}\text { Person in a 2-adult household, no children, } \\
\text { household head aged } 50 \text { and with at least a } \\
\text { diploma, both normally working, living in the } \\
\text { North of the country. }\end{array}$ & 0.002 & 1.59 & 0.04 & 0.007 & 1.79 & 0.07 \\
\hline B & As above, plus 2 children & 0.007 & 1.93 & 0.09 & 0.011 & 1.91 & 0.09 \\
\hline $\mathrm{C}$ & As above, plus spouse not working & 0.023 & 2.44 & 0.17 & 0.017 & 2.03 & 0.10 \\
\hline $\mathrm{D}$ & As above, plus inactive head & 0.059 & 3.23 & 0.30 & 0.021 & 2.26 & 0.14 \\
\hline $\mathrm{E}$ & As above, plus head with low education & 0.125 & 4.13 & 0.46 & 0.046 & 2.71 & 0.22 \\
\hline $\mathrm{F}$ & As above, plus living in the South & 0.248 & 5.82 & 0.78 & 0.115 & 4.05 & 0.48 \\
\hline G & As above, plus young head (age 30) & 0.260 & 5.96 & 0.81 & 0.143 & 4.73 & 0.61 \\
\hline $\mathrm{H}$ & $\begin{array}{l}\text { As above, plus single-mother aged } 25 \text { with } \\
\text { three children }\end{array}$ & 0.298 & 6.14 & 0.84 & 0.195 & 4.61 & 0.59 \\
\hline I & As above, plus a living-in elderly & 0.290 & 5.46 & 0.71 & 0.198 & 4.57 & 0.58 \\
\hline $\mathrm{L}$ & As case G, but head is unemployed & 0.467 & 6.72 & 0.95 & 0.279 & 5.90 & 0.83 \\
\hline M & $\begin{array}{l}\text { Elderly couple, no children, head aged 75, with } \\
\text { high education, retired, spouse not working, } \\
\text { living in the North }\end{array}$ & 0.007 & 1.97 & 0.10 & 0.007 & 1.60 & 0.05 \\
\hline $\mathrm{N}$ & As above, plus head low education & 0.033 & 2.53 & 0.18 & 0.031 & 2.18 & 0.13 \\
\hline $\mathrm{O}$ & As above, plus living in the South & 0.086 & 3.87 & 0.42 & 0.083 & 3.15 & 0.31 \\
\hline $\mathrm{P}$ & As above, plus a living-in non working adult & 0.125 & 4.23 & 0.49 & 0.096 & 3.44 & 0.36 \\
\hline Q & As above, plus head aged 85 & 0.144 & 5.41 & 0.71 & 0.113 & 3.78 & 0.43 \\
\hline $\mathrm{R}$ & As case B, but head is self-employed & 0.023 & 2.12 & 0.12 & 0.008 & 1.74 & 0.06 \\
\hline S & As above, plus 1 member with health problems & 0.283 & 5.35 & 0.69 & 0.238 & 4.64 & 0.59 \\
\hline
\end{tabular}

Notes: Simulations for those just starting a poverty spell, using estimated parameters and variables as in Table 5. Multiple Spell Approach.

The entry probability is estimated by Prob(poor in $\mathrm{t} \mid$ non poor in $\mathrm{t}-1 ; \mathrm{X}$ ), using the same models as in Table 4, specification 1. 


\section{APPENDIX}

\section{Table A1: Exits/entries in life-style deprivation and in each item deprivation}

\begin{tabular}{|c|c|c|c|}
\hline & $\begin{array}{c}\% \text { of } \\
\text { individuals } \\
\text { deprived } \\
\text { of the item }\end{array}$ & $\begin{array}{l}\text { Item deprivation } \\
\text { exit rate }\end{array}$ & $\begin{array}{l}\text { Item deprivation } \\
\text { entry rate }\end{array}$ \\
\hline Color tv & 1.0 & 72.84 & 0.56 \\
\hline Dishwasher & 19.6 & 51.4 & 11.86 \\
\hline home adequately warm & 23.0 & 32.92 & 8.55 \\
\hline annual holiday away from home for a week's & 41.5 & 22.04 & 16.11 \\
\hline second hand clothes & 13.4 & 50.19 & 7.94 \\
\hline replacing any worm-out furniture & 60.9 & 18.07 & 31.24 \\
\hline car o van & 2.6 & 64.14 & 1.6 \\
\hline video recorder & 9.4 & 58.63 & 4.98 \\
\hline Arrears & 5.9 & 60.64 & 3.52 \\
\hline Telephone & 2.7 & 60.66 & 1.47 \\
\hline eat meat or fish every other day & 6.4 & 57.21 & 3.51 \\
\hline $\begin{array}{l}\text { friends or family for a drink or meal at least once } \\
\text { a month }\end{array}$ & 5.9 & 44.72 & 9.37 \\
\hline Microwave & 11.2 & 63.4 & 7.55 \\
\hline
\end{tabular}

Notes: w1-w8 pooled sample. Deprivation threshold is $75 \%$ median deprivation score.

Exit rates $=$ Prob(not deprived in the items in year $\mathrm{t} \mid$ deprived in the item in year $\mathrm{t}-1$ ).

Deprivation re-entry $=$ Prob(deprived in the items in year $\mathrm{t} \mid$ not deprived in the item in year $\mathrm{t}-1$ ).

Table A2: Descriptive statistics.

\begin{tabular}{lrrrrrr}
\hline \multicolumn{1}{c}{ All } & \multicolumn{2}{c}{ Income poverty } & \multicolumn{2}{c}{$\begin{array}{c}\text { Life } \\
\text { style deprived }\end{array}$} \\
\hline \multicolumn{1}{c}{ Variable } & Mean & Std. Dev. & Mean & Std. Dev. & Mean & Std. Dev. \\
\hline number of children & 0.75 & 1.04 & 1.07 & 1.39 & 0.93 & 1.15 \\
no. persons aged 18-64 & 2.50 & 1.41 & 2.83 & 1.61 & 2.68 & 1.65 \\
no. persons aged 65+ & 0.35 & 0.64 & 0.26 & 0.53 & 0.33 & 0.62 \\
no. of workers & 0.70 & 0.84 & 0.40 & 0.69 & 0.50 & 0.82 \\
Child & 0.18 & 0.39 & 0.23 & 0.42 & 0.21 & 0.41 \\
Old & 0.18 & 0.38 & 0.14 & 0.35 & 0.17 & 0.38 \\
Female & 0.51 & 0.50 & 0.53 & 0.50 & 0.53 & 0.50 \\
age of household head & 52.6 & 14.6 & 52.0 & 14.2 & 52.7 & 15.3 \\
female household head & 0.18 & 0.39 & 0.20 & 0.40 & 0.23 & 0.42 \\
low education of household head & 0.64 & 0.48 & 0.84 & 0.36 & 0.82 & 0.38 \\
high education of househ. head & 0.08 & 0.27 & 0.02 & 0.14 & 0.02 & 0.14 \\
head working $<15$ hours weekly & 0.01 & 0.10 & 0.02 & 0.14 & 0.02 & 0.15 \\
Unemployed househ. head & 0.03 & 0.17 & 0.09 & 0.29 & 0.09 & 0.29 \\
Discouraged househ. head & 0.01 & 0.07 & 0.01 & 0.12 & 0.01 & 0.12 \\
Inactive househ. head & 0.35 & 0.48 & 0.33 & 0.47 & 0.37 & 0.48 \\
North & 0.49 & 0.50 & 0.23 & 0.42 & 0.25 & 0.43 \\
South & 0.29 & 0.45 & 0.59 & 0.49 & 0.57 & 0.49 \\
No. health problems in the hh & 0.29 & 0.58 & 0.28 & 0.57 & 0.35 & 0.63 \\
Separated/divorced & 0.12 & 0.33 & 0.15 & 0.35 & 0.17 & 0.37 \\
single & 0.05 & 0.22 & 0.05 & 0.21 & 0.06 & 0.24 \\
Single parent & 0.01 & 0.12 & 0.02 & 0.13 & 0.02 & 0.14 \\
self employed househ.head & 0.19 & 0.39 & 0.25 & 0.43 & 0.13 & 0.34 \\
\hline Notes: w1-w8 pooled sample. & & & & & & \\
\hline
\end{tabular}




\section{Notes:}

${ }^{\mathrm{i}}$ Only a very few papers have studied poverty in Italy using individual longitudinal data. OECD (2001) uses the first 3 waves of the ECHP to study the transitions in and out of low income for a number of countries, including Italy. Other studies include Brandolini et. al. (2002), Addabbo (2000) and Giraldo et. al. (2002), all of which rely on the data from the Bank of Italy's Survey on Household Income and Wealth (SHIW). However, the SHIW has a number of limitations for study of the duration of poverty at the individual level. First, its panel component is very small; second, its bi-annual release makes it impossible to detect poverty spells that last less than two years (which, as we will see, are numerous); finally, the survey does not contain the necessary information to construct indicators of multidimensional deprivation.

${ }^{\text {ii }}$ As available panel data are typically too short to analyze an individual's first entry in poverty, the focus in the following will be on the length of time spent below the poverty line for those who are observed to enter poverty within the observation window offered by the data.

iii In the extreme case in which the individual is completely unable to borrow against future income (i.e. is completely liquidity constrained), the duration in consumption poverty is expected to be smaller than the duration in income poverty. The intuition is that, while dissaving enables consumption to drop with some time lag with respect to the income shock, the presence of liquidity constraints implies that consumption subsequently recovers in parallel with income. In an online Appendix we show this is indeed the case, by computing the optimal consumption of a representative household head facing liquidity constraints and a stochastic income flow for which properties are derived from the income observed in our panel data.

iv See Peracchi (2002) for further details on the ECHP.

${ }^{v}$ The OECD equivalence scale assigns weight 1 to the head, 0.7 to each additional adult and 0.5 to each child. The modified scale assigns weights $1,0.5$ and 0.3 , respectively. The results do not change appreciably when using either scale.

${ }^{v i}$ The life-style score $S_{i}$ is computed as the weighted average of all non-missing items: $S_{i}=\sum_{j} w_{j} 1\left(D_{i j}=1\right) /\left[\sum_{j} w_{j} 1\left(D_{i j}=1\right.\right.$ or $\left.\left.D_{i j}=0\right)\right]$, where $0 \leq S_{i} \leq 1, D_{i j}$ is the set of $J$ dummy indicators $(J=13), w_{j}$ is the corresponding weight and $1(\cdot)$ is the indicator function. Accordingly, $S_{i}$ exists even if some items are missing, unless more than 3 items are missing, in which case we force $S_{i}$ to also be missing. The results were very similar when $S_{i}$ was defined to be missing if any of the 13 items was missing; in fact, in this case $S_{i}$ was missing for only 3 percent of the observations.

vii We also produce "relative" versions of our life-style deprivation indicators, by using wave-specific weights for each of the items that make up $\mathrm{S}_{\mathrm{i}}$ and also set the threshold at fractions of the contemporaneous median of $\mathrm{S}_{\mathrm{i}}$, as opposed to the wave 1 median. The results, available from the authors, do not change appreciably from those reported in the paper, and are not shown.

viii During the period, the Gini coefficient declined from 0.33 in 1991 to 0.29 in 2001.

${ }^{\text {ix }}$ The median of $S_{i}$ is 0.90 , implying that the majority of the population can afford at least 90 percent of the (weighted) set of items included in our life-style deprivation score. The mean of $S_{i}$ grew from 0.86 in 1994 to 0.88 in 2001 . The $75^{\text {th }}$ percentiles and above are 1 in all years, and the $25^{\text {th }}$ is 0.76 in 1994 and grows at 0.83 in 2001 ; the $10^{\text {th }}$ percentile grew from 0.60 to 0.68 during the sample period.

${ }^{\mathrm{x}}$ The results obtained with the time-varying income poverty line, including our multivariate hazard-rate models, are very similar to those obtained with the fixed line and are available from the authors upon request.

${ }^{\mathrm{xi}}$ The variable excludes the household head, whose labour market status is captured by a series of dummies.

xii The result holds even if the number of self-employed members of the household is used instead.

xiii Because the probability of being below the poverty line for four consecutive years is much lower than the cross-sectional poverty rates, the magnitude of the marginal effects are now also smaller than before.

${ }^{\text {xiv }}$ Given that that the number of poor individuals is larger than the number of those in life-style deprivation, one could rescale this probability by the ratio of the incidence of the two types of deprivation (equal to 0.93 from Table 1), to obtain a "measure of mismatch" that lies between the 0 to 100 percent range. Even so, the rescaled probability is only 0.4 .

${ }^{\mathrm{xv}}$ Aasvee et al. (2995), Jenkins (2002), Cappellari and Jenkins (2004) provide excellent reviews of the various approaches to modelling poverty dynamics.

${ }^{x v i}$ This means that, with the 8 waves of the ECHP, an escape from poverty can only occur in any of the next six survey years following the one in which the individual has first fallen into poverty. Including this last year, therefore, every individual can be observed from one to a maximum of seven interviews in poverty. A similar reasoning holds for out-of-poverty spells.

xvii See Arranz and Cantò (2010) for a recent exception.

xviii Table A1 shows much turnover in each constituent item of our LSD measure.

xix The results obtained when separately estimating the exit and re-entry rates, with no control for unobserved heterogeneity, do not differ much from the ones reported here, but generally provide a worse fit of the data. These alternative estimates are available upon request from the authors.

${ }^{\mathrm{xx}}$ At about 15 percent of its GDP, Italy has the highest level of pension spending in Europe.

${ }^{x x i}$ We also performed the estimation separately for those in the South and those in the North. In fact, the baseline hazard/duration terms were statistically different for the two areas, implying somewhat longer durations in the South. However, the differences in the magnitude of the estimated baseline coefficients were small, implying that most of the effect had already been captured by the intercept shift included in the model specification. For simplicity—and given that in the simulation exercises of Table 9 the different baseline hazards were not producing appreciable differences with respect to the specification with a North/South intercept only-we have opted to report estimates for this simpler model only.

${ }_{\text {xxii }}$ A few variables are statistically significant in the re-entry rates for one poverty definitions but not the other: the quadratic in the age of the household head and the coefficient of elderly individuals are only significant for LSD; female headship is only significant for IP. However, note that the signs of these variables are consistent across the two definitions.

${ }_{\text {xxiii }}$ A Wald test to determine whether the six duration dummies are jointly statistically insignificant is easily rejected at conventional levels for both poverty definitions.

${ }^{\text {xxiv }}$ The distribution $G$ is left unspecified so as to minimize misspecification biases, and is approximated by a bivariate discrete distribution with a number of support points to be determined by the data. As in most random-effect models, we assume that $\theta^{P}$ and $\theta^{N}$ are uncorrelated with the observed heterogeneity included in the vectors of covariates. 
${ }^{x x v}$ The model was initially estimated with six support points, but it did not converge, indicating that the data would not allow such a general specification for the unobserved heterogeneity distribution. The model was then re-estimated by constraining at zero some of the mass probabilities.

${ }^{\text {xxvi }}$ Unrestricted year effects were included in the models of Table 8 (but not shown) to account for macroeconomic trends and the general trend of reduction in poverty rates in Table 1; the simulations in Table 9 assume average year effects. 